\title{
GÊNESE E CLASSIFICAÇÃO DOS SOLOS DE UMA TOPOSSEQUÊNCIA EM ÁREA DE CARSTE NA SERRA DA BODOQUENA, MS ${ }^{(1)}$
}

\author{
Marlen Barros e Silva ${ }^{(2)}$, Lúcia Helena Cunha dos Anjos ${ }^{(3)}$, Marcos Gervasio Pereira ${ }^{(3)}$, \\ Jolimar Antônio Schiavo(4), Miguel Cooper ${ }^{(5)}$ \& Rafael de Souza Cavassani ${ }^{(6)}$
}

\section{RESUMO}

Pouco se conhece sobre os solos dos sistemas cársticos carbonáticos no Brasil, apesar da sua importância e reconhecida fragilidade. Os objetivos deste estudo foram avaliar a gênese de solos desenvolvidos de rochas calcárias e materiais derivados e caracterizar os atributos desses, contribuindo para o Sistema Brasileiro de Classificação de Solos (SiBCS). Foram estudados três perfis de solos em uma topossequência na Serra da Bodoquena, MS, dispostos nas posições de sopé (P1), terço médio (P2) e topo (P3) de encosta suave-ondulada com pendente longa e perfil longitudinal plano-convexo-plano. Todos os perfis são profundos, com cores bruno-escura nos horizontes superficiais e avermelhada em subsuperfície, além de textura argilosa com incremento de argila em profundidade. $O$ íon cálcio predomina no complexo sortivo, bem como a fração humina entre as frações húmicas. A micromorfologia dos solos revela feições de iluviação de argila em associação com feições de acumulações de $\mathrm{CaCO}_{3}$. Porém, em nenhum dos perfis, os teores de $\mathrm{CaCO}_{3}$ equivalente foram suficientes para o reconhecimento do horizonte cálcico e, ou, petrocálcico, ou de caráter carbonático ou hipocarbonático. Com sequência de horizontes A-Bt (P1); A-E-Bt (P2); e A-Bi (P3), os solos apresentam a seguinte ordem de evolução pedogenética: $\mathrm{P} 1>$ P2 > P3. De acordo com o SiBCS, os solos são classificados como Argissolo Vermelho eutrófico nitossólico (P1); Argissolo Vermelho distrófico típico (P2); e Cambissolo Háplico Tb eutrófico típico

(1) Trabalho extraído da Tese de Doutorado da primeira autora, financiado pelo CNPq - Edital MCT/CNPq 14/2009. Recebido para publicação em 26 de setembro de 2012 e aprovado em 5 de setembro de 2013 .

(2) Doutoranda do Curso de Pós-graduação em Agronomia da Universidade Federal Rural do Rio de Janeiro (UFRRJ). Professora Assistente IV da Universidade Estadual do Maranhão (UEMA). E-mail: marlenbs@ufrrj.br

(3) Professor Associado IV, Departamento de Solos, Universidade Federal Rural do Rio de Janeiro (UFRRJ). BR 465, km 7. CEP 23890-000 Seropédica (RJ). Bolsista 1D do CNPq e Cientista do Nosso Estado da FAPERJ. E-mail: lanjos@ufrrj.br, gervasio@ufrrj.br

(4) Professor Adjunto IV da Universidade Estadual do Mato Grosso. Rodovia Aquidauana, km 12. CEP $79200-000$ Mato Grosso do Sul (MS). E-mail: schiarv@uems.br

(5) Professor Associado, Departamento de Ciência do Solo, Escola Superior de Agricultura "Luiz de Queiroz", USP. Av. Pádua Dias, 11. CEP 13418-900 Piracicaba (SP). Bolsista 2 do CNPq. E-mail: mcooper@usp.br

(6) Discente do Curso de Agronomia da Universidade Federal Rural do Rio de Janeiro (UFRRJ). Bolsista de iniciação ciéntífica do CNPq. E-mail: rafaelcavassani@ufrrj.br 
(P3). Para todos os perfis, no quinto nível aplica-se a classe de atividade de argila Tm (atividade média), validando proposta recente do SiBCS.

Termos de indexação: sistema cárstico, SiBCS, micromorfologia do solo.

\title{
SUMMARY: GENESIS AND CLASSIFICATION OF SOILS IN A TOPOSEQUENCE OF KARST IN SERRA DA BODOQUENA (MS)
}

\begin{abstract}
Despite their importance and vulnerability, little is known about the soils in the calcareous karst systems in Brazil. The objective of this study was to evaluate the genesis of soils formed from calcareous parent materials and to characterize their properties, as a contribution to the Brazilian Soil Classification System (SiBCS). Three profiles located at footslope (P1), backslope (P2) and summit (P3) positions in a toposequence with slightly undulated relief, were studied in the Serra da Bodoquena, Mato Grosso do Sul State. All profiles were relatively deep, with dark brown surface horizons and reddish in the subsurface, clayey texture and increasing clay content in deeper layers. Calcium was the dominant exchangeable cation, and humin the main fraction of soil organic matter. Soil micromorphology showed clay illuviation features associated to $\mathrm{CaCO}_{3}$ accumulation. However, the $\mathrm{CaCO}_{3}$ levels were insufficient in the profiles to characterize a calcic or petrocalcic horizon or carbonatic diagnostic properties. The horizons in the profiles were arranged: $A-B t(P 1) ; A-E-B t(P 2)$ and $A-B w(P 3)$, and the evolution of the soil genesis in the order - P1>P2>P3. According to the SiBCS, the profiles were classified as eutrophic Red Argisol (P1), dystric Red Argisol (P2), and eutrophic Tb Haplic Cambisol (P3) (equivalent to Udalf, Udult and Udept sub-orders in the USDA Soil Taxonomy, respectively). For all profiles, at the family level the class medium activity clay (Tm) was applied, validating a recent proposal to the SiBCS.
\end{abstract}

Index terms: karst system, Brazilian Soil Classification System, soil micromorphology.

\section{INTRODUÇÃO}

O Planalto da Bodoquena ou Serra da Bodoquena propriamente dita, localizado no sudeste do Estado do Mato Grosso do Sul, representa um dos mais extensos e importantes sistemas cársticos do Brasil. Apesar de possuir abundância de feições como cavernas, sumidouros, ressurgências e tufas calcárias, já foi considerado incompletamente desenvolvido em razão da rede de drenagem predominantemente superficial, fato incomum em carstes carbonáticos (Kohler, 1994).

Para Almeida (1965), o retardamento no desenvolvimento do carste da Bodoquena deve-se à geologia da região, constituída por uma intercalação de rochas carbonáticas e terrígenas das Formações Tamengo, Cerradinho, Guaicurus e Bocaina, todas do Grupo Corumbá, haja vista que a presença de minerais não carbonáticos nessas rochas reduz a sua velocidade de dissolução. Além da composição mineralógica das rochas, também o clima e o relevo são fatores determinantes no desenvolvimento de um carste, na medida em que influenciam o fluxo da água de percolação, considerado o principal agente responsável pela esculturação do modelado cárstico e formação dos solos. Para Bosák (2003), a carstificação é um fenômeno poligenético e policíclico dependente diretamente da energia hidrodinâmica do sistema.

Segundo Zaslavsky \& Rogowski (1969), tanto em sistemas cársticos como não cársticos, o grau de evolução pedogenética está diretamente associado ao fluxo de água nos solos, o que depende não apenas da declividade, como da forma da superfície e posição na vertente. Na base das encostas, pedoformas côncavas condicionam fluxo de água convergente, proporcionando maior infiltração da água no solo e menores perdas por erosão com maior desenvolvimento pedogenético; no terço superior, a convexidade da superfície favorece maior fluxo lateral da água e escoamento superficial, com menor evolução dos solos por causa da intensificação do processo erosivo.

Estudos desenvolvidos em topossequências em diferentes regiões amazônicas por Campos et al. (2010, 2012) demonstraram o efeito da posição na paisagem sobre a variabilidade espacial dos atributos dos solos e seu desenvolvimento, encontrando-se os mais profundos na posição de topo, onde a estabilidade da superfície favorece a menor variabilidade dos atributos, enquanto nas vertentes e no sopé dessas o menor desenvolvimento pedogenético implica em maiores variações nos valores dos atributos dos solos. A forma da superfície e a posição na paisagem influenciam a pedogênese também em carstes de litologia carbonática em regiões de clima árido ou semiárido, conforme observado por Ruellan (2006) e Sedov et al. (2008). Esses pesquisadores verificaram a relação entre a geoquímica, a profundidade e a espessura das acumulações de $\mathrm{CaCO}_{3}$ e a posição dos solos nas encostas, concentrando-se a ocorrência de horizontes cálcicos e petrocálcicos nas áreas de contorno côncavo localizadas no sopé das vertentes, onde a infiltração da água favorece também maior 
espessura e profundidade de acumulação dos carbonatos.

No Brasil, apesar de representarem uma área significativa - cerca de $6 \%$ do território nacional e de sua natural fragilidade física - os sistemas cársticos ainda permanecem em boa parte desconhecidos, sobretudo no que refere-se à sua cobertura pedológica. Entre os trabalhos realizados em áreas de carste carbonático com o fim de investigar a gênese e, ou, distribuição dos solos na paisagem, pode-se citar o de Lynch (2009), o qual verificou o predomínio de Chernossolos no terço inferior, Nitossolos na meia encosta e Latossolos no terço superior e topo de uma topossequência na região de Planaltina, GO. Em carste carbonático na Chapada do Apodi, entre o Ceará e Rio Grande do Norte, foram observados Cambissolos eutróficos e Chernossolos rêndzicos no lado potiguar da chapada, enquanto no lado cearense encontram-se mapeados Cambissolos Háplicos eutróficos, Vertissolos, Neossolos Litólicos eutróficos (Embrapa, 1973) e Latossolos Vermelho-Amarelos eutróficos, todos argilosos (Silva, 1973). Apesar de a ocorrência de horizontes cálcicos já ter sido reportada em algumas regiões do país, nenhum horizonte petrocálcico foi identificado até o momento. No território nacional, ao contrário do verificado em outras regiões de clima árido ou semiárido, a baixa disponibilidade de água no sistema promove a lixiviação dos carbonatos dos horizontes superficiais do solo pelas águas de percolação e sua posterior reprecipitação em subsuperfície, com a consequente formação de horizontes cálcicos e petrocálcicos. Tais horizontes, reconhecidos no SiBCS como diagnósticos, são considerados ótimos indicadores paleoclimáticos e paleoambientais (Mack et al., 1994), sobretudo quando as feições cálcicas encontram-se associadas às feições de iluviação de argila, indicando variações climáticas (Reheis, 1987; Dal' Bó \& Basilici, 2010).

Dessa forma, ainda há muito a ser compreendido sobre a gênese de solos em sistemas cársticos, sob condições de clima tropical. Nesse sentido, este trabalho teve como hipóteses que o material de origem carbonático e o clima favorecem a formação de horizonte cálcico e até mesmo petrocálcico na Serra da Bodoquena, nas condições de relevo dos perfis estudados. Os objetivos deste estudo foram avaliar a gênese de solos desenvolvidos a partir de rochas calcárias e a caraterização dos atributos químicos, físicos, mineralógicos e micromorfológicos, de forma a contribuir para o Sistema Brasileiro de Classificação de Solos (SiBCS).

\section{MATERIAL E MÉTODOS}

A área do estudo localiza-se no Planalto da Bodoquena, no município de Bodoquena, MS, entre as latitudes de $20^{\circ} 32^{\prime} 11^{\prime \prime}$ e $20^{\circ} 34^{\prime} 13^{\prime \prime} \mathrm{S}$ e longitudes de $56^{\circ} 40^{\prime} 43^{\prime \prime}$ e $56^{\circ} 44^{\prime} 13^{\prime \prime}$ W. O clima é do tipo Aw - tropical úmido da classificação de Köppen, com temperatura média anual de $23,9^{\circ} \mathrm{C}$ e pluviosidade média anual entre 1.200 e $1.500 \mathrm{~mm}$, com inverno seco que se estende de abril a setembro e verão chuvoso entre os meses de outubro a março. A região, originalmente recoberta pela vegetação de transição Floresta Estacional Decidual Submontana/Savana, encontra-se atualmente com pastagem.

A Serra da Bodoquena apresenta topografia assimétrica, com encostas escarpadas a oeste e suavemente inclinadas a leste, que coalescem com a planície de inundação do rio Miranda (Brasil, 1982). Entre os flancos oriental e ocidental ocorrem áreas deprimidas que formam vales em manjedoura, onde existem feições características do relevo cárstico, entre as quais dolinas, surgências, ressurgências e sumidouros. A geologia da Serra é dominada pelo Grupo Corumbá, constituído da base para o topo pelas Formações Cerradinho, Bocaina, Tamengo e Guaicurus, compostas predominantemente por calcários calcíticos e dolomíticos, além de folhelhos, margas, arenitos, arcósios e siltitos (Boggiani et al., 1996). A topossequência estudada apresenta como material de origem rochas de natureza calcária da Formação Bocaina, do Grupo Corumbá (Figura 1).

Os perfis de solos estão dispostos ao longo de uma topossequência localizada ao norte da Serra da Bodoquena, em área de planalto com relevo suaveondulado e elevação variável entre 303 e 343 m, onde foram descritos e coletados três perfis nas posições de: sopé (P1), terço médio (P2) e topo (P3) de encosta (Quadro 1). A descrição morfológica, as coletas de amostras deformadas para determinações analíticas e indeformadas para a densidade do solo (Ds) e os testes de efervescência com solução de $\mathrm{HCl}$ e $\mathrm{H}_{2} \mathrm{O}_{2}$ foram realizados segundo Santos et al. (2005). Foram coletadas amostras indeformadas e orientadas para análises micromorfológicas de alguns horizontes com o auxílio de caixas de papelão nas dimensões $5 \times 7 \times$ $10 \mathrm{~cm}$ (Castro et al., 2003). Os solos foram classificados de acordo com o Sistema Brasileiro de Classificação de Solos - SiBCS (Embrapa, 2013).

As análises químicas e físicas da terra fina seca ao ar (TFSA), realizadas de acordo com os métodos propostos por Embrapa (1997), brevemente resumidos neste item, compreenderam: composição granulométrica (com uso do hexametafosfato de sódio como dispersante); densidade do solo (Ds) pelo método do anel de Kopecky; densidade de partículas (Dp) pelo balão volumétrico e cálculo do volume total de poros do solo (VTP). O pH foi determinado em água e em KCl $1 \mathrm{~mol} \mathrm{~L}^{-1}$; $\mathrm{Ca}^{2+} \mathrm{e} \mathrm{Mg}^{2+}$, extração com $\mathrm{KCl} 1 \mathrm{~mol} \mathrm{~L}^{-1}$ e quantificação por complexometria; $\mathrm{Na}^{+} \mathrm{e} \mathrm{K}^{+}$, via extração com solução de $\mathrm{HCl} 0,05 \mathrm{~mol} \mathrm{~L}^{-1}$ e $\mathrm{H}_{2} \mathrm{SO}_{4} 0,0125 \mathrm{~mol} \mathrm{~L}^{-1}$ e determinação por fotometria de chama; $\mathrm{Al}^{3+}$ extraído com solução de $\mathrm{KCl} 1 \mathrm{~mol} \mathrm{~L}^{-1}$ e determinado por titulação; e acidez extraível $(\mathrm{Al}+\mathrm{H})$ extraída com solução de acetato de cálcio $1 \mathrm{~mol} \mathrm{~L}^{-1}$ ajustada a pH 7,0 e determinada por titulação. O P foi extraído por Mehlich-1 e solução de Olsen para efeito 


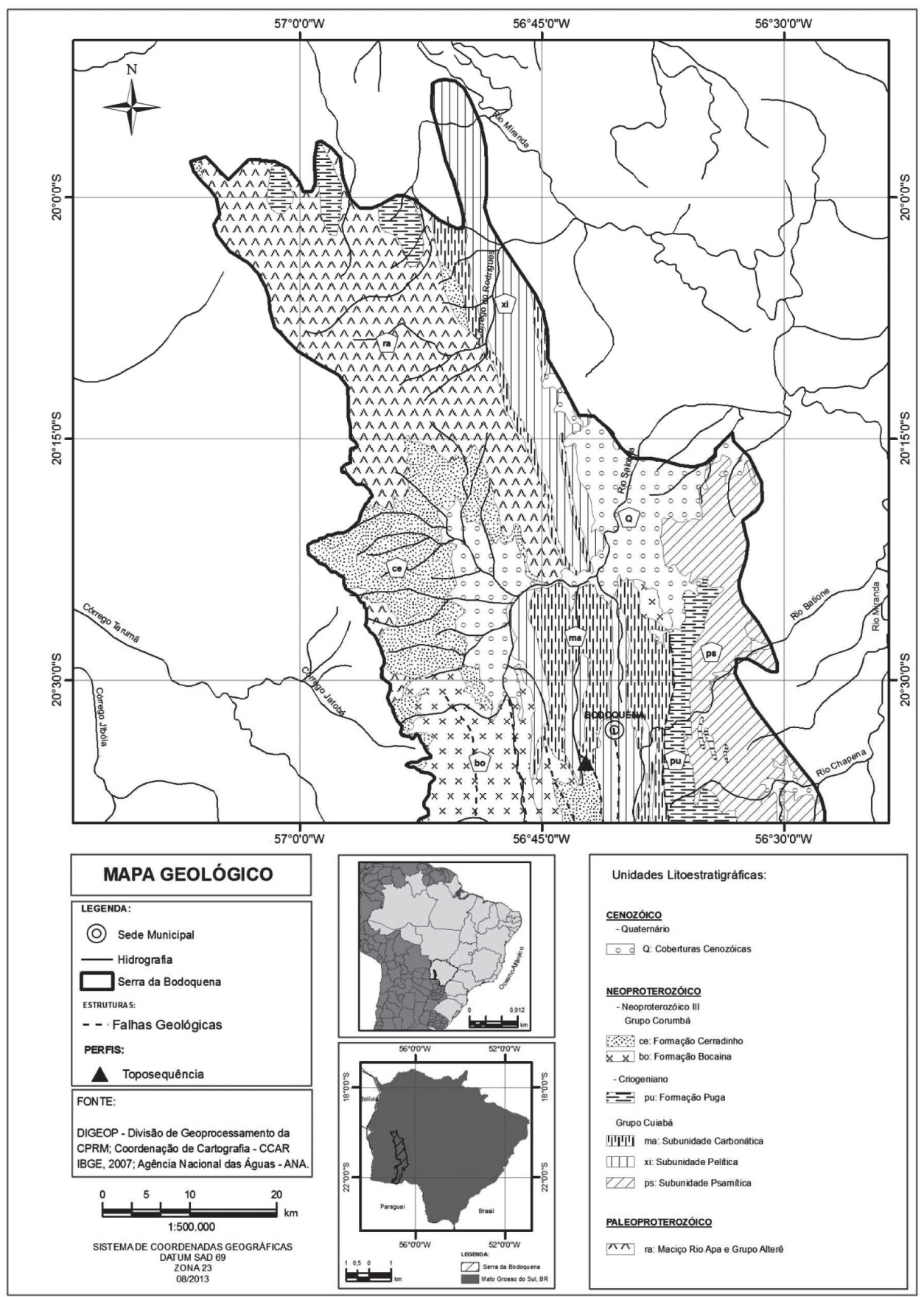

Figura 1. Mapa de localização da área estudada e geologia da porção norte da Serra da Bodoquena, MS.

Quadro 1. Informações gerais dos solos em topossequência na Serra da Bodoquena, MS

\begin{tabular}{|c|c|c|c|c|c|c|c|c|c|}
\hline Perfil & $\begin{array}{l}\text { Coordenadas } \\
\text { Lat./Long. }\end{array}$ & $\begin{array}{c}\text { Elev } \\
\text { m }\end{array}$ & $\begin{array}{c}\text { Relevo } \\
\text { local }\end{array}$ & $\begin{array}{c}\text { Posição na } \\
\text { encosta }\end{array}$ & $\begin{array}{l}\text { Forma da } \\
\text { superficie }\end{array}$ & $\begin{array}{c}\text { Material } \\
\text { de origem }\end{array}$ & $\begin{array}{c}\text { Drenagem } \\
\text { Moderad. }\end{array}$ & $\begin{array}{c}\text { Vegetação } \\
\text { atual }\end{array}$ & $\begin{array}{c}\text { Pedregosidade } \\
\text { Rochosidade }\end{array}$ \\
\hline $\mathrm{P} 1$ & $\begin{array}{l}20^{\circ} 33^{\prime} 45,45^{\prime \prime} \\
56^{\circ} 41^{\prime} 24,83^{\prime \prime}\end{array}$ & 303 & Plano & Sopé & Plana & $\begin{array}{l}\text { Calcários da } \\
\text { Form. Bocaina }\end{array}$ & drenado & Pastagem & Ausente \\
\hline $\mathrm{P} 2$ & $\begin{array}{l}20^{\circ} 33^{\prime} 49,09^{\prime \prime} \\
56^{\circ} 41^{\prime} 39,84^{\prime \prime}\end{array}$ & 334 & $\begin{array}{c}\text { Suave } \\
\text { ondulado }\end{array}$ & $\begin{array}{l}\text { Terço } \\
\text { médio }\end{array}$ & Convexa & $\begin{array}{l}\text { Calcários da } \\
\text { Form. Bocaina }\end{array}$ & $\begin{array}{c}\text { Moderad. } \\
\text { drenado }\end{array}$ & Pastagem & Ausente \\
\hline P3 & $\begin{array}{l}20^{\circ} 33^{\prime} 45,05^{\prime \prime} \\
56^{\circ} 41^{\prime} 54,91^{\prime \prime}\end{array}$ & 343 & Plano & Topo & Plana & $\begin{array}{l}\text { Calcários da } \\
\text { Form. Bocaina }\end{array}$ & $\begin{array}{c}\text { Moderad. } \\
\text { drenado }\end{array}$ & $\begin{array}{l}\text { Capoeira } \\
\text { alta }\end{array}$ & $\begin{array}{l}\text { Lig. pedregosa/ } \\
\text { Lig. rochosa }\end{array}$ \\
\hline
\end{tabular}

Lat./Long.: Latitude/Longitude; Elev.: Elevação; Moderad.: Moderadamente; e Lig.: Ligeiramente. 
de comparação, uma vez que o método Mehlich-1 tende a superestimar os teores de $\mathrm{P}$ em solos de origem calcária.

Os teores de $\mathrm{CaCO}_{3}$ equivalente foram determinados por ataque ácido com $\mathrm{HCl} 0,5 \mathrm{~mol} \mathrm{~L}^{-1} \mathrm{e}$ titulação com solução de $\mathrm{NaOH}$ padrão (Embrapa, 1997). A caracterização dos óxidos foi realizada via ataque sulfúrico com solução de $\mathrm{H}_{2} \mathrm{SO}_{4}$ 1:1 em fervura por $30 \mathrm{~min}$ sob refluxo e posterior resfriamento e filtragem, determinando por colorimetria os teores de $\mathrm{Fe}$, Al e Ti e, no resíduo, o de Si, para cálculo dos índices $\mathrm{Ki}$ e Kr. Os óxidos de Fe pedogênicos representados como $\mathrm{Fe}_{0}$ e $\mathrm{Fe}_{\mathrm{d}}$ foram extraídos, respectivamente, com oxalato ácido de amônio $0,2 \mathrm{~mol} \mathrm{~L}^{-1}$ (Schwertmann, 1964, modificado por Schulze, 1984) e solução de ditionito-citrato-bicarbonato de sódio (Mehra \& Jackson, 1960), com quatro extrações por amostra.

$\mathrm{O}$ carbono orgânico total foi determinado pela oxidação com $\mathrm{K}_{2} \mathrm{Cr}_{2} \mathrm{O}_{7} 0,4 \mathrm{~mol} \mathrm{~L}^{-1} \mathrm{em}$ meio sulfúrico e titulação com $\mathrm{Fe}\left(\mathrm{NH}_{4}\right)_{2} \cdot\left(\mathrm{SO}_{4}\right)_{2} \cdot 6 \mathrm{H}_{2} \mathrm{O} 0,1 \mathrm{~mol} \mathrm{~L}^{-1} \mathrm{e}$ realizado o fracionamento químico da matéria orgânica pelo método proposto pela Sociedade Internacional de Substâncias Húmicas (IHSS), com adaptações por Benites et al. (2003). A extração da matéria orgânica foi feita com $\mathrm{NaOH} 0,1 \mathrm{~mol} \mathrm{~L}^{-1}$ e a determinação do carbono das frações da matéria orgânica foi realizada com $\mathrm{K}_{2} \mathrm{Cr}_{2} \mathrm{O}_{7}$ 0,4 mol L-1 , obtendo-se o C-FAF, C-FAH e C-HUM.

Quanto à análise micromorfológica para confecção de lâminas delgadas, após terem sido secas ao ar por 20 dias e depois em estufa a $35{ }^{\circ} \mathrm{C}$ por sete dias, as amostras foram impregnadas com uma mistura de resina poliéster, monômero de estireno e pigmento fluorescente, usando Butanox como catalisador para a polimerização da resina (Castro et al., 2003). Após a preparação das lâminas com espessura máxima de $30 \mu \mathrm{m}$, seguiu-se a sua análise em microscópio ótico polarizante Zeiss e lupa binocular Wild, ambos sob luz normal e polarizada. As descrições seguiram os critérios e terminologia proposta por Stoops (2003) e Bullock et al. (1985).

\section{RESULTADOS E DISCUSSÃO}

A topossequência está localizada em área de relevo suave-ondulado com cerca de $4 \%$ de declividade. Segundo o modelo de paisagem proposto por Troeh (1965), mesmo em condições de baixa declividade como nessa topossequência, pequenas variações forma de superfície condicionam padrão diferenciado dos atributos dos solos, na medida em que determinam diferenças na distribuição do fluxo de água e processos pedogenéticos; as pedoformas côncavas proporcionam maior desenvolvimento pedogenético em razão da maior infiltração da água no solo; e nas superfícies convexas predominam solos menos evoluídos, em razão da intensificação do processo erosivo. Em relação à posição na topossequência, o perfil 1 (P1) está situado no sopé da encosta, em pedoforma plana; o perfil 2 (P2) localiza-se no terço médio, em superfície convexa; e o perfil 3 (P3) encontra-se no topo da encosta, em relevo plano.

\section{Atributos morfológicos}

O P1 apresenta sequência de horizontes A-Bt, com horizonte superficial A com $26 \mathrm{~cm}$ de espessura e cores brunadas no matiz 10YR, enquanto na meia encosta o P2 possui horizonte A parcialmente decapitado pela erosão hídrica, com $19 \mathrm{~cm}$ de espessura e cores nos matizes 7,5YR e 5YR e sequência de horizontes A-EBt (Quadro 2). O P3, com sequência A-Bi, apresenta A com $36 \mathrm{~cm}$ de espessura e matizes 10YR a 5YR. A menor espessura do horizonte superficial A na meia encosta parece resultar do processo de erosão superficial favorecido pela convexidade da superfície em área de pastagem mal manejada. Analisando o efeito de diferentes pedoformas na distribuição espacial dos atributos do solo, também Sanchez et al. (2009) constataram menor espessura dos horizontes superficiais dos solos em superfícies convexas, haja vista as maiores perdas por erosão ocorrerem nessas superfícies por causa do predomínio do fluxo divergente (Zaslavsky \& Rogowski, 1969).

Em subsuperfície, os três perfis apresentam mosqueados vermelhos nos matizes $7,5 \mathrm{YR}, 5 \mathrm{YR}$ e 2,5YR e matriz avermelhada nos matizes $2,5 \mathrm{YR}$ a $5 \mathrm{YR}$. A cor vermelha é uma característica comum em solos desenvolvidos a partir de rochas carbonáticas e denotativa da presença de hematita, cuja formação é favorecida em condições de $\mathrm{pH}$ elevado e drenagem desimpedida (Schwertmann \& Taylor, 1989). Sob condições climáticas semelhantes à da serra da Bodoquena, a gênese de solos hematíticos derivados de calcários duros na região mediterrânica tem sido atribuída ao processo de rubefação, que para acontecer requer índices pluviométricos superiores a $700 \mathrm{~mm} /$ ano e acentuada sazonalidade climática (Boero et al., 1992). A sazonalidade climática é necessária para que nos períodos secos ocorram a precipitação do Fe liberado pelo intemperismo dos silicatos presentes na rocha calcária na forma de impurezas e o rearranjamento de formas menos cristalinas como a ferridrita, com a consequente gênese da hematita pedogênica (Lynch, 2009).

Quanto à textura, é argilosa nos horizontes superficiais e muito argilosa nos subsuperficiais, com presença de cerosidade - indicativa da iluviação de argila, comum a abundante nos horizontes Bt1 e Bt2 do P1, e comum no horizonte Bt1 do P2. Os três perfis apresentam agregação com estrutura granular associada a blocos subangulares, com grau de desenvolvimento variando de fraco a forte nos horizontes superficiais. Nos horizontes subsuperficiais, a estrutura apresenta-se em blocos angulares e subangulares, variando de forte no $\mathrm{P} 1$ à fraca no $\mathrm{P} 3$. No P3, a agregação em blocos subangulares fracamente desenvolvida no horizonte $\mathrm{B}$, associada às 
Quadro 2. Atributos morfológicos dos solos em topossequência na Serra da Bodoquena, MS

\begin{tabular}{|c|c|c|c|c|c|c|}
\hline \multirow{2}{*}{ Hor. } & \multirow{2}{*}{ Prof. } & \multicolumn{2}{|c|}{ Cor Munsell } & \multirow{2}{*}{ Estrutura $^{(2)}$} & \multirow{2}{*}{ Cerosidade $^{(3)}$} & \multirow{2}{*}{ Classe textural } \\
\hline & & Matriz & Mosq. ${ }^{(1)}$ & & & \\
\hline \multicolumn{7}{|c|}{$\mathrm{cm}$} \\
\hline \multicolumn{7}{|c|}{ Sopé $(\mathrm{P} 1)$} \\
\hline Ap & $0-18$ & 10YR $3 / 2$ & - & fr., pq., gr. e mo. pq. e me., bsa. & - & franco-argilosa \\
\hline $\mathrm{AB}$ & $18-26$ & 10YR $3 / 2$ & - & fr., pq, gr. e mo., pq. e me., bsa. & - & franco-argilossiltosa \\
\hline BA & $26-42$ & $7,5 \mathrm{YR} 3 / 4$ & 7,5 YR $3 / 2$ & mo., pq. e me., bsa. e mo., mpq., ba. & - & argilosa \\
\hline Bt1 & $42-78$ & $2,5 \mathrm{YR} 3 / 6$ & - & fo., me., gr. e mo., me., bsa. e ba. & co. e mo. & argilosa \\
\hline Bt2 & \multicolumn{5}{|c|}{ Terço médio (P2) } & muito argilosa \\
\hline Ap & $0-11$ & $7,5 \mathrm{YR} 3 / 3$ & - & mo., pq, gr. e mo. pq., bsa. & - & argilosa \\
\hline A & $11-19$ & $5 \mathrm{YR} 3 / 3$ & $5 \mathrm{YR} 4 / 6$ & mo., pq. e me., bsa. & - & franco-argilosa \\
\hline $\mathrm{E}$ & $19-30$ & $5 Y R \quad 4 / 4$ & $5 \mathrm{YR} 4 / 2$ & mo., pq. e me., ba. & - & franco-argilosa \\
\hline Bt1 & $30-53$ & $5 Y R 4 / 4$ & $5 \mathrm{YR} 4 / 3$ & mo., pq. e me., ba. & co. e fr. & franco-argilosa \\
\hline Bt2 & $53-83$ & $2,5 \mathrm{YR} 4 / 4$ & - & mo., pq., ba. & - & argilosa \\
\hline $\mathrm{B} / \mathrm{C}$ & \multicolumn{5}{|c|}{ Topo $(\mathrm{P} 3)$} & muito argilosa \\
\hline A1 & $0-14$ & 10YR $2 / 2$ & - & fo., me. e gd., gr. e mo. pq., bsa. & - & franco-argilossiltosa \\
\hline A 2 & $14-24$ & 10YR 3/1 & - & mo., pq., gr. e mo., pq. e me. bsa. & - & argilossiltosa \\
\hline $\mathrm{AB}$ & $24-36$ & $5 \mathrm{YR} 3 / 2$ & $5 \mathrm{YR} 3 / 4$ & mo., me., ba. e fr., pq., bsa. & - & argilosa \\
\hline \multirow[t]{2}{*}{$\mathrm{BA}$} & $36-47$ & $5 \mathrm{YR} 3 / 3$ & $7,5 \mathrm{YR} 4 / 2$ & & & \\
\hline & & & $2,5 Y R \quad 3 / 4$ & fr., me., ba. e fr., pq. bsa. & - & muito argilosa \\
\hline Bi1 & $47-74$ & $2,5 \mathrm{YR} 4 / 4$ & $2,5 \mathrm{YR} 3 / 4$ & mo., me., ba. e bsa. & - & muito argilosa \\
\hline $\mathrm{Bi} 2$ & $74-103$ & $2,5 \mathrm{YR} 3 / 6$ & - & fr., me., ba. e mo., pq., bsa. & - & argilosa \\
\hline $\mathrm{B} / \mathrm{C}$ & $103-124+$ & $2,5 \mathrm{YR} 4 / 4$ & - & fr., pq. e me., ba. e bsa. & - & muito argilosa \\
\hline
\end{tabular}

Hor: horizonte; Prof: profundidade; ${ }^{(1)}$ Mosq.: mosqueado; ${ }^{(2)}$ fr: fraca; mo: moderada; fo: forte; mpq: muito pequena; pq: pequena; me: média; ba:blocos angulares; bsa: blocos subangulares; gr: granular; ${ }^{(3)}$ co: comum; ab: abundante; e pr: proeminente.

pontuações de minerais primários e fragmentos de rochas, além da ausência de processo pedogenético dominante, denota o incipiente desenvolvimento desse horizonte. A consistência úmida varia de friável a firme nos horizontes superficiais e friável, nos horizontes subsuperficiais. Todos os horizontes dos três perfis apresentam consistência plástica a muito plástica e pegajosa a muito pegajosa.

Verifica-se a ocorrência de ligeira pedregosidade e rochosidade no P3, caracterizado pela presença de afloramentos rochosos de natureza calcária, bem como de um matacão calcário a cerca de $50 \mathrm{~cm}$ de profundidade, além de pontuações de minerais primários em subsuperfície. Nos horizontes subsuperficiais de todos os perfis ocorrem nódulos ferromanganosos do tipo "chumbinho de caça", comumente em associação com pontuações de carbonatos de cálcio. Segundo Oliveira et al. (2001), a presença desses nódulos, comuns nos solos derivados de calcário do norte de Minas Gerais, indica a ocorrência de possíveis alterações no regime hídrico dos solos, que devem ter passado por alternância de condições de alagamento e aeração exigidas para a redução, movimentação e precipitação dos íons Fe e Mn. No entanto, a coexistência de concreções ferromanganosas com pontuações de carbonato de cálcio parece indicar clima atual mais seco, responsável pela preservação do $\mathrm{CaCO}_{3}$ nos perfis.

\section{Atributos físicos}

Verifica-se em todos os perfis o predomínio da fração argila, com teores entre $270 \mathrm{~g} \mathrm{~kg}^{-1}$ no horizonte $\mathrm{E}$ do P2 e $740 \mathrm{~g} \mathrm{~kg}^{-1}$ no Bt2 do P1, sendo somente no P1 e $\mathrm{P} 2$ verificada a ocorrência de cerosidade no horizonte B. A fração silte é expressiva, com valores entre 180 e $450 \mathrm{~g} \mathrm{~kg}^{-1}$, próximos aos já reportados em pesquisas também no sistema cárstico da Bodoquena (Embrapa, 2007; Pereira et al., 2013) (Quadro 3). Para Anjos et al. (1998), a presença de média a alta porcentagem de silte indica a incompleta alteração do material. A relação silte/argila, utilizada como índice auxiliar do grau de intemperismo de solos tropicais e diferenciação entre horizontes B latossólicos e B incipientes (Embrapa, 2013), apresentou valores inferiores a 0,8 no horizonte $\mathrm{B}$ diagnóstico nos três perfis estudados, indicando uma condição de intemperismo mais avançado. Tais resultados são semelhantes aos verificados em outros solos carbonáticos na Bodoquena por Pereira et al. (2013); na região Nordeste, por Silva (1973); e em Lagoa Santa, MG, por Shinzato (1998). 
Quadro 3. Atributos físicos dos solos em topossequência na Serra da Bodoquena, MS

\begin{tabular}{|c|c|c|c|c|c|c|c|c|c|c|c|c|}
\hline \multirow{2}{*}{ Hor } & \multirow{2}{*}{ Prof. } & \multicolumn{2}{|c|}{ Areia } & \multirow{2}{*}{ Silte } & \multicolumn{2}{|c|}{ Argila } & \multirow{2}{*}{$\mathbf{G F}^{(1)}$} & \multirow{2}{*}{$\mathrm{AG} / \mathrm{AF}^{(2)}$} & \multirow{2}{*}{ Silte/Argila } & \multirow{2}{*}{$D p^{(3)}$} & \multirow{2}{*}{$\mathrm{Ds}^{(4)}$} & \multirow{2}{*}{$\operatorname{VTP}^{(5)}$} \\
\hline & & Grossa & Fina & & Total & Natural & & & & & & \\
\hline & $\mathrm{cm}$ & & & $\mathrm{g} \mathrm{kg}^{-1}$ & & & \multicolumn{2}{|l|}{$\%$} & & \multicolumn{2}{|c|}{$\mathrm{Mg} \mathrm{m}^{-3}$} & $\%$ \\
\hline \multicolumn{13}{|c|}{ Sopé (P1) } \\
\hline Ap & $0-18$ & 130 & 100 & 430 & 340 & 65 & 81 & 1,30 & 1,26 & 2,63 & 1,17 & 55 \\
\hline $\mathrm{AB}$ & $18-26$ & 100 & 100 & 420 & 380 & 59 & 84 & 1,00 & 1,11 & 2,64 & 1,27 & 52 \\
\hline $\mathrm{BA}$ & $26-42$ & 90 & 80 & 380 & 450 & 71 & 84 & 1,13 & 0,84 & 2,68 & 1,25 & 53 \\
\hline Bt1 & $42-78$ & 60 & 60 & 300 & 580 & 11 & 98 & 1,00 & 0,52 & 2,67 & 1,41 & 47 \\
\hline Bt2 & $78-120+$ & 40 & 30 & 190 & 740 & 8 & 99 & 1,33 & 0,26 & 2,88 & 1,41 & 51 \\
\hline \multicolumn{13}{|c|}{ Terço médio (P2) } \\
\hline Ap & $0-11$ & 160 & 80 & 360 & 400 & 70 & 83 & 2,00 & 0,90 & 2,55 & 1,38 & 46 \\
\hline $\mathrm{A}$ & $11-19$ & 140 & 90 & 410 & 360 & 85 & 76 & 1,56 & 1,14 & 2,60 & 1,34 & 48 \\
\hline $\mathrm{E}$ & $19-30$ & 160 & 120 & 450 & 270 & 80 & 70 & 1,33 & 1,67 & 2,68 & 1,37 & 49 \\
\hline Bt1 & $30-53$ & 130 & 70 & 350 & 450 & 27 & 94 & 1,86 & 0,78 & 2,66 & 1,36 & 49 \\
\hline Bt2 & $53-83$ & 100 & 60 & 280 & 560 & 11 & 98 & 1,67 & 0,50 & 2,70 & 1,56 & 42 \\
\hline $\mathrm{B} / \mathrm{C}$ & $83-120+$ & 90 & 30 & 180 & 700 & 5 & 99 & 3,00 & 0,26 & 2,78 & 1,36 & 51 \\
\hline \multicolumn{13}{|c|}{ Topo (P3) } \\
\hline $\mathrm{A} 1$ & $0-14$ & 70 & 80 & 450 & 400 & 45 & 89 & 0,88 & 1,13 & 2,60 & 1,30 & 50 \\
\hline $\mathrm{A} 2$ & $14-24$ & 80 & 70 & 410 & 440 & 45 & 90 & 1,14 & 0,93 & 2,58 & 1,17 & 55 \\
\hline $\mathrm{AB}$ & $24-36$ & 90 & 60 & 320 & 530 & 64 & 88 & 1,50 & 0,60 & 2,54 & 1,03 & 59 \\
\hline $\mathrm{BA}$ & $36-47$ & 80 & 40 & 270 & 610 & 49 & 92 & 2,00 & 0,44 & 2,69 & 1,12 & 58 \\
\hline Bi1 & $47-74$ & 70 & 40 & 230 & 660 & 38 & 94 & 1,75 & 0,35 & 2,67 & 1,17 & 56 \\
\hline $\mathrm{Bi} 2$ & 74-103 & 80 & 50 & 280 & 590 & 42 & 93 & 1,60 & 0,47 & 2,69 & 1,33 & 51 \\
\hline $\mathrm{B} / \mathrm{C}$ & $103-124+$ & 60 & 30 & 270 & 640 & 13 & 98 & 2,00 & 0,42 & 2,73 & 2,73 & 2,73 \\
\hline
\end{tabular}

Hor: horizonte; Prof: profundidade; (1) GF: grau de floculação; ${ }^{(2)}$ AG/AF: relação areia grossa e areia fina; ${ }^{(3)}$ Dp: densidade de partículas; ${ }^{(4)}$ Ds: densidade do solo; e ${ }^{(5)}$ VTP: volume total de poros do solo.

Para Shinzato (1998), entretanto, a relação silte/argila não deve ser usada como indicadora do grau de intemperismo em solos cujo material de origem é sedimentar, como o calcário.

O grau de floculação, crescente em profundidade, varia entre 70 e $99 \%$ e apresenta estreita correspondência com o teor de argila por causa do maior desenvolvimento de estrutura e da estabilidade dos agregados nos horizontes subsuperficiais, conferido pela maior concentração de óxidos de Fe no horizonte B dos perfis bem como em razão da menor concentração de compostos orgânicos. Os valores de densidade de partículas $(\mathrm{Dp})$ concentram-se entre 2,55 e $2,88 \mathrm{Mg} \mathrm{m}^{-3}$, com pequena variação entre os horizontes, o que sugere a ocorrência de materiais minerais de natureza semelhante, enquanto a densidade do solo (Ds) varia entre 1,03 e $1,41 \mathrm{Mg} \mathrm{g}^{-3}$, com tendência de aumento em profundidade nos perfis P1 e P2, acompanhando o incremento de argila e a redução nos teores de matéria orgânica em profundidade. Em relação à posição na encosta, os menores valores de Ds no horizonte superficial são observados no sopé, onde a deposição de matéria orgânica é favorecida. Resultados semelhantes foram reportados por Nizeyimana \& Bicki (1992) em uma topossequência no norte de Ruanda, ao verificarem diminuição da densidade do solo e aumento no conteúdo do carbono orgânico com a diminuição do declive da meia encosta para o sopé de deposição.

\section{Atributos químicos}

Os valores de $\mathrm{pH}$ em $\mathrm{KCl}$ variam entre 3,9 e 5,0 e os de $\mathrm{pH}$ em água entre 5,3 e 6,7, na classe de reação moderadamente ácida a praticamente neutra (Embrapa, 2006), à semelhança de resultados encontrados em outros solos derivados de calcário na região Sudeste do Brasil (Shinzato, 1998) (Quadro 4). No P3 ocorre aumento nos valores de $\mathrm{pH}$ em água em profundidade acompanhando a variação do íon cálcio, enquanto no P1 e P2 não se verifica variação entre horizontes.

Os valores de $\Delta \mathrm{pH}\left[\mathrm{pH}(\mathrm{KCl})-\mathrm{pH}\left(\mathrm{H}_{2} \mathrm{O}\right)\right]$ são negativos em todos os perfis, indicando o predomínio de cargas negativas na superfície dos coloides do solo.

Observam-se teores mais elevados de $\mathrm{Ca}^{2+}$, soma de bases, saturação por bases e $\mathrm{CaCO}_{3}$ equivalente no P1 e P3, ambos em pedoformas planas. No P1, onde os teores decrescem com a profundidade, isto se deve, provavelmente, ao enriquecimento por adição de íons das partes mais altas da topossequência, já que o perfil está localizado em posição favorável à coluviação, enquanto no P3, a presença de calhaus e matacões calcários em superfície e em subsuperficie devem estar 
Quadro 4. Atributos químicos dos solos em topossequência na Serra da Bodoquena, MS

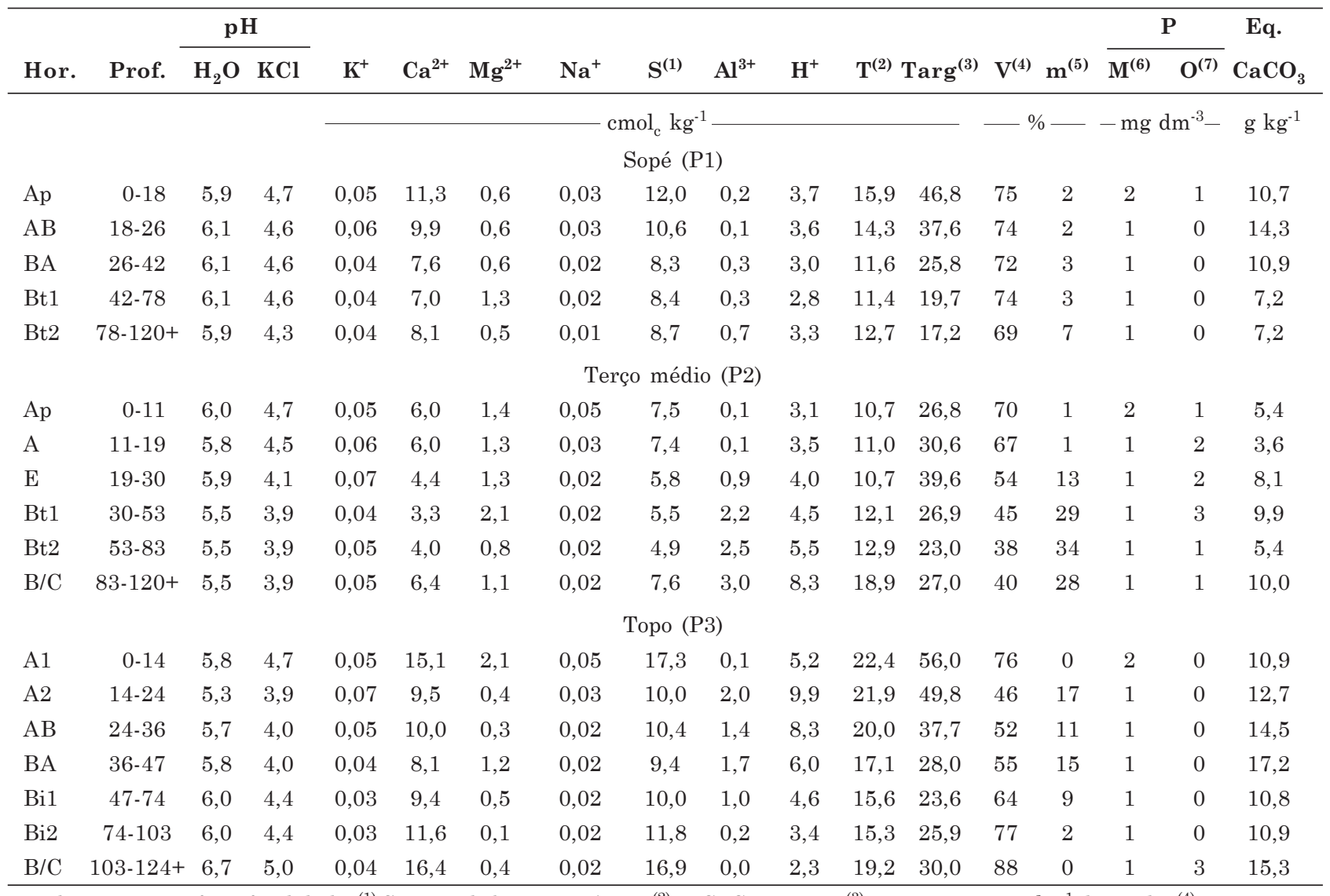

Hor: horizonte; Prof: profundidade; (1) S: soma de bases trocáveis; ${ }^{(2)} \mathrm{T}$ : CTC a pH 7,0; ${ }^{(3)}$ Targ: T x 1000/g kg ${ }^{-1}$ de argila; ${ }^{(4)}$ V: saturação por bases; ${ }^{(5)} \mathrm{m}$ : saturação por alumínio; ${ }^{(6)} \mathrm{M}$ : fósforo extraído pelo método Mehlich-1; e ${ }^{(7)} \mathrm{O}$ : fósforo extraído pelo método de Olsen.

contribuindo com a adição de $\mathrm{Ca}^{2+}$ no perfil. Coerente com a natureza calcítica das rochas calcárias que predominam na região, o $\mathrm{Ca}^{2+}$ é o íon predominante no complexo sortivo, com teores variáveis entre 3,3 e $16,4 \mathrm{cmol}_{\mathrm{c}} \mathrm{kg}^{-1}$, seguido pelo $\mathrm{Mg}^{2+}$. Os teores de $\mathrm{K}^{+} \mathrm{e}$ $\mathrm{Na}^{+}$são baixos em todos os perfis, sendo respectivamente inferiores a 0,07 e $0,05 \mathrm{cmol}_{\mathrm{c}} \mathrm{kg}^{-1}$, com pouca variação em profundidade e entre perfis.

Observam-se teores de $\mathrm{Al}^{+3}$ variáveis entre $0,1 \mathrm{e}$ $0,7 \mathrm{cmol}_{\mathrm{c}} \mathrm{kg}^{-1}$, no P1; entre 0,1 e $3,0 \mathrm{cmol}_{\mathrm{c}} \mathrm{kg}^{-1}$, no $\mathrm{P} 2$; e entre 0,0 e $2,0 \mathrm{cmol}_{\mathrm{c}} \mathrm{kg}^{-1}$, no P3, com valor de saturação por $\mathrm{Al}$ máximo de $34 \%$ no horizonte $\mathrm{Bt} 2$, do P2. O aumento nos teores de $\mathrm{Al}^{+3} \mathrm{em}$ subsuperfície, sobretudo no perfil $\mathrm{P} 2$, coincide com redução nos valores de Ki, o que se acredita estar relacionado a uma variação na mineralogia da argila nesses horizontes. Em relação ao P, observam-se baixos teores desse elemento $\left(\leq 2 \mathrm{mg} \mathrm{dm}^{-3}\right)$, corroborando os resultados encontrados em solos carbonáticos afins, tanto no domínio do semiárido (Silva, 1973) quanto no sudeste brasileiro (Shinzato, 1998; Lynch, 2009). Em razão das baixas concentrações de $\mathrm{CaCO}_{3}$ equivalente nos perfis, não foram observadas diferenças entre os valores de $\mathrm{P}$ extraídos pelos métodos de Mehlich-1 e de Olsen, este último mais recomendado para solos carbonáticos por extrair somente as formas lábeis do elemento (Braida et al., 1996). Quanto à saturação por bases, $\mathrm{P} 1$ e P3 são eutróficos e o P2 é distrófico epieutrófico. Somente no P3, observa-se em subsuperfície valor de CTC da argila $\geq 27,0 \mathrm{cmol}_{\mathrm{c}} \mathrm{kg}^{-1}$, que define a presença de argila de alta atividade (Ta), mas apenas no horizonte BA $\left(28,0 \mathrm{cmol}_{\mathrm{c}} \mathrm{kg}^{-1}\right)$. No entanto, o valor de atividade da argila nos horizontes Bt1 dos perfis $\mathrm{P} 1 \mathrm{e}$ P2 foi de 19,7 e $26,9 \mathrm{cmol}_{\mathrm{c}} \mathrm{kg}^{-1}$, respectivamente, próximos ao limite para atividade alta.

Em todos os perfis, os teores de $\mathrm{CaCO}_{3}$ equivalente, inferiores a 17,2 $\mathrm{g} \mathrm{kg}^{-1}$, estão abaixo dos exigidos para identificação de caráter hipocarbonático, carbonático, horizonte cálcico ou petrocálcico, segundo o SiBCS (Embrapa, 2013), o que se atribui ao clima topical chuvoso da região que, associado à estabilidade da superfície, à topografia suave ondulada e à drenagem da área, favorece a solubilização e lixiviação dos carbonatos dos solos na forma de bicarbonatos. Ao longo da topossequência, os teores mais elevados de $\mathrm{CaCO}_{3}$ equivalente são observados no P3, onde se distribuem de forma uniforme entre os horizontes; e no $\mathrm{P} 1$, onde os maiores teores ocorrem nos horizontes superficiais. 
Os teores de $\mathrm{SiO}_{2}$ variam de 164 a $272 \mathrm{~g} \mathrm{~kg}^{-1}$; $\mathrm{Al}_{2} \mathrm{O}_{3}$, de 87 a $199 \mathrm{~g} \mathrm{~kg}^{-1} ; \mathrm{Fe}_{2} \mathrm{O}_{3}$, de 41 a $76 \mathrm{~g} \mathrm{~kg}^{-1}$; e o $\mathrm{TiO}_{2}$, de 2,2 a 4,7 $\mathrm{g} \mathrm{kg}^{-1}$ (Quadro 5). Em relação ao $\mathrm{SiO}_{2}, \mathrm{Al}_{2} \mathrm{O}_{3}$ e $\mathrm{Fe}_{2} \mathrm{O}_{3}$, observou-se correspondência entre esses valores e o teor de argila, com aumento gradual com a profundidade acompanhando o incremento de argila. Os baixos teores de Ti e Fe refletem a pobreza da rocha calcária nesses elementos, como já verificado por Cunha et al. (1999) em solos calcimórficos de Corumbá, MS. A relação Ki variou de 1,96 a 2,36 nos horizontes subsuperficiais, com os mínimos e máximos, respectivamente, em Bt1 e Bt2, ambos no P1. Esses valores são comparáveis aos de outros solos brasileiros, onde a caulinita figura como principal argilomineral. Os valores estimados para a atividade da fração argila, calculada para o horizonte B desses solos, sugerem a participação de argilominerais de camada 2:1.

Observando-se os teores das formas de Fe de alta e baixa cristalinidade $\left(\mathrm{Fe}_{\mathrm{d}}\right)$ e a relação $\mathrm{Fe}_{\mathrm{d}} / \mathrm{Fe}_{\mathrm{t}}$, verificase predomínio do $\mathrm{Fe}_{\mathrm{d}}$ em todos os horizontes dos três perfis, com teores compreendidos entre 25,2 e $53,2 \mathrm{~g} \mathrm{~kg}^{-1}$, superiores aos encontrados para solos calcários do nordeste do Brasil (Cunha et al., 1999; Corrêa et al., 2003), o que se deve à maior precipitação pluvial da região em estudo, que, associada às condições de drenagem da área, resultou na precipitação de óxidos de $\mathrm{Fe}$ de maior grau de cristalinidade, especialmente hematita. $\mathrm{O}$ aumento nos valores de $\mathrm{Fe}_{\mathrm{d}}$ em subsuperfície acompanha o incremento nos teores de argila em razão da migração conjunta de argilominerais e óxidos. Entretanto, a relação $\mathrm{Fe}_{0} / \mathrm{Fe}_{\mathrm{d}}$ e o $\mathrm{Fe}_{\mathrm{o}}$ foram mais altos nos horizontes superficiais dos perfis, o que se deve aos maiores teores de compostos orgânicos nesses horizontes e ao seu efeito na inibição da cristalização dos óxidos (Schwertmann \& Taylor, 1989).

\section{Carbono orgânico total (COT) e frações húmicas}

Todos os horizontes superficiais são de constituição mineral. Independentemente da posição na paisagem e da forma da superfície, em todos os perfis o COT decresce em profundidade, com teores variáveis entre 14,2 e 29,6 $\mathrm{g} \mathrm{kg}^{-1}$, em superfície, e entre 6,3 e 21,2 g $\mathrm{kg}^{-1}$, em subsuperfície (Quadro 6), conforme padrão comumente observado nos solos minerais. Entre os perfis, o P2 apresentou os menores teores de COT em superfície, o que se deve, provavelmente, às perdas de solo por maior escorrimento superficial em área de pastagem mal manejada, favorecidas pela forma convexa da superfície na meia encosta. Os maiores teores de COT são observados no P1 e P3, localizados em superfícies planas.

Quadro 5. Teores dos óxidos pedogenéticos, relações Ki e Kr, teores de ferro ditionito citrato bicarbonato de sódio $\left(\mathrm{Fe}_{\mathrm{d}}\right)$ e oxalato ácido de amônio $\left(\mathrm{Fe}_{\mathrm{o}}\right)$ e suas relações

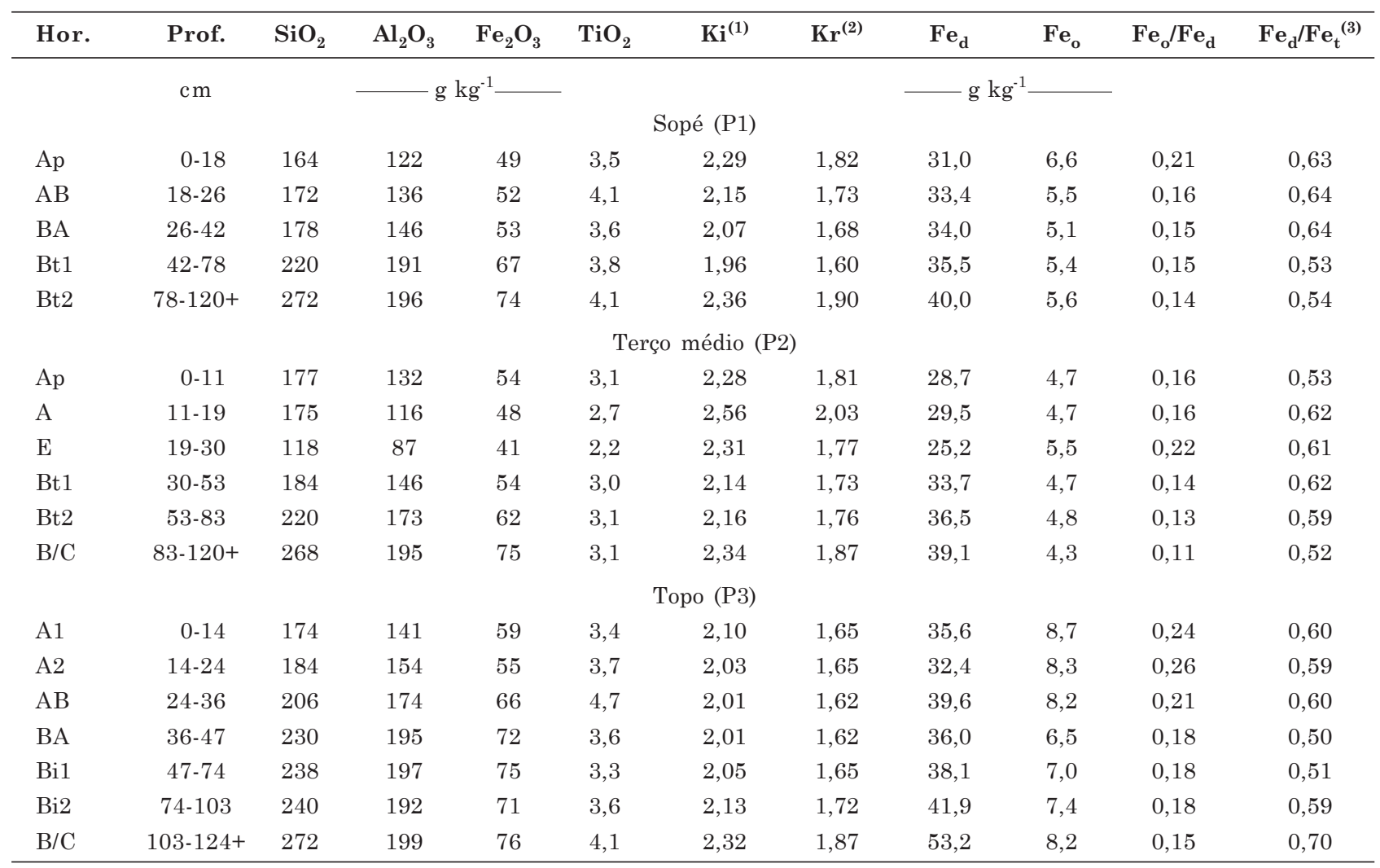

Hor.: horizonte; Prof.: profundidade; ${ }^{(1)} \mathrm{Ki}=\left(\mathrm{SiO}_{2} / \mathrm{Al}_{2} \mathrm{O}_{3}\right)^{*} 1,7 ;{ }^{(2)} \mathrm{Kr}=\left[\mathrm{SiO}_{2}{ }^{*} 1,7\right) /\left(\mathrm{Al}_{2} \mathrm{O}_{3}+\left(0,64{ }^{*} \mathrm{Fe}_{2} \mathrm{O}_{3}\right)\right] ; \mathrm{e}^{(3)} \mathrm{Fe}_{\mathrm{T}}: \mathrm{Fe}_{2} \mathrm{O}_{3}$. 
Quadro 6. Carbono total (COT), carbono das frações húmicas e relações entre frações dos solos em topossequência na Serra da Bodoquena, MS

\begin{tabular}{|c|c|c|c|c|c|c|c|}
\hline Hor. & Prof. & COT & C-Hum ${ }^{(1)}$ & C-FAH ${ }^{(2)}$ & C-FAF ${ }^{(3)}$ & C-FAH/C-FAF ${ }^{(4)}$ & C-EA/C-Hum ${ }^{(5)}$ \\
\hline & $\mathrm{cm}$ & \multicolumn{4}{|c|}{$-\mathrm{g} \mathrm{kg}^{-1}$} & & \\
\hline \multicolumn{8}{|c|}{ Sopé (P1) } \\
\hline Ap & $0-18$ & 29,6 & 18,0 & 4,0 & 2,5 & 1,60 & 0,36 \\
\hline $\mathrm{AB}$ & $18-26$ & 21,7 & 11,8 & 2,2 & 3,2 & 0,69 & 0,46 \\
\hline BA & $26-42$ & 21,2 & 10,0 & 3,2 & 3,4 & 0,94 & 0,66 \\
\hline Bt1 & $42-78$ & 10,2 & 3,5 & 1,4 & 2,2 & 0,64 & 1,03 \\
\hline Bt2 & $78-120+$ & 8,7 & 4,3 & 2,2 & 0,7 & 3,14 & 0,67 \\
\hline \multicolumn{8}{|c|}{ Terço médio (P2) } \\
\hline Ap & $0-11$ & 17,4 & 7,5 & 2,6 & 2,2 & 1,18 & 0,64 \\
\hline $\mathrm{A}$ & $11-19$ & 14,2 & 12,1 & 2,3 & 2,1 & 1,10 & 0,36 \\
\hline $\mathrm{E}$ & $19-30$ & 14,4 & 13,1 & 2,2 & 2,5 & 0,88 & 0,36 \\
\hline Bt1 & $30-53$ & 10,6 & 7,3 & 2,2 & 1,0 & 2,20 & 0,44 \\
\hline Bt2 & $53-83$ & 6,6 & 4,1 & 1,2 & 1,2 & 1,00 & 0,59 \\
\hline $\mathrm{B} / \mathrm{C}$ & $83-120+$ & 6,3 & 4,4 & 1,0 & 1,2 & 0,83 & 0,50 \\
\hline \multicolumn{8}{|c|}{ Topo (P3) } \\
\hline $\mathrm{A} 1$ & $0-14$ & 28,9 & 15,7 & 2,0 & 2,6 & 0,77 & 0,29 \\
\hline $\mathrm{A} 2$ & $14-24$ & 25,9 & 14,3 & 1,9 & 2,0 & 0,95 & 0,27 \\
\hline $\mathrm{AB}$ & $24-36$ & 18,7 & 11,0 & 2,7 & 2,6 & 1,04 & 0,48 \\
\hline $\mathrm{BA}$ & $36-47$ & 11,6 & 4,9 & 2,4 & 1,4 & 1,71 & 0,78 \\
\hline Bi1 & $47-74$ & 11,2 & 7,8 & 4,3 & 1,9 & 2,26 & 0,79 \\
\hline Bi2 & 74-103 & 9,2 & 3,3 & 1,7 & 1,5 & 1,13 & 0,97 \\
\hline $\mathrm{B} / \mathrm{C}$ & $103-124+$ & 8,5 & 5,0 & 1,3 & 1,5 & 0,87 & 0,56 \\
\hline
\end{tabular}

Hor.: horizonte; Prof.: profundidade; ${ }^{(1)} \mathrm{C}$-Hum: carbono da fração humina; ${ }^{(2)} \mathrm{C}-\mathrm{FAH}$ : carbono na fração ácido húmico; ${ }^{(3)} \mathrm{C}$ FAF: carbono na fração ácido fúlvico; ${ }^{(4)} \mathrm{C}-\mathrm{FAH} / \mathrm{C}-\mathrm{FAF}$ : relação entre carbono na fração ácido húmico e na fração ácido fúlvico; $\mathrm{e}^{(5)} \mathrm{C}$-EA/C-Hum: relação entre o extrato alcalino (C-FAH + C-FAF) e o C-Hum.

A distribuição das frações húmicas segue o mesmo padrão do COT, com maiores teores nos horizontes A e decréscimo em profundidade, sendo o maior percentual correspondente à fração humina (C-Hum). Para Stevenson (1994), a predominância da fração humina em relação às frações alcalinossolúveis devese a diversos fatores, dentre os quais se destacam a elevada massa molecular dos compostos insolúveis e a forte interação desses com a fração mineral dos solos, o que lhes confere maior resistência à degradação pelos microrganismos. A existência de duas estações climáticas bem definidas na região (uma chuvosa e outra seca) também contribui para a predominância de C-Hum, na medida em que favorece a desidratação dos compostos orgânicos na época seca e a rápida formação de compostos de elevado peso molecular, mais estáveis na estação úmida (Manzatto, 1990). Padrão semelhante foi observado por Fontana et al. (2010), Ebelling et al. (2011) e Pereira et al. (2013), em outros solos com teores elevados de carbonatos em razão da formação de compostos organominerais de alta estabilidade.

A relação C-EA/C-Hum varia entre 0,27 e 1,03, valores considerados baixos e indicativos da insolubilidade da matéria orgânica e alta estabilidade entre essa e a matriz mineral dos solos (Fontana et al., 2010). Em profundidade, observa-se tendência de aumento na relação C-EA/C-Hum, acompanhando o incremento de argila. A influência da textura do solo sobre a mineralização/imobilização da matéria orgânica já havia sido observada por Mtambanengwe et al. (2004), em solos de diferentes texturas, os quais verificaram haver correlação negativa entre a mineralização dos compostos orgânicos e o teor de argila, corroborando as observações de Fontana et al. (2001).

\section{Micromorfologia}

Todos os três perfis apresentam material pedal, com microestrutura do tipo granular e em blocos subangulares, moderadamente desenvolvida no horizonte A, e em blocos subangulares, com grau de pedalidade variando de moderado a forte, nos horizontes subsuperficiais (Quadro 7).

No P1, o horizonte Ap apresenta pedalidade com microestrutura granular e em blocos subangulares, com distribuição relativa do tipo porfírica aberta e relação g/f (com limite de $2 \mu \mathrm{m}$ ) de $3 / 2$. O material grosso, predominantemente constituído por grãos de quartzo pobremente selecionados, representa cerca de 
Quadro 7. Descrição micromorfológica dos horizontes selecionados dos solos

\begin{tabular}{|c|c|c|c|c|c|c|}
\hline Hor. & Zona & $\begin{array}{l}\text { Distribuição } \\
\text { relativa }\end{array}$ & $\mathrm{FB}^{(1)}$ & $\begin{array}{l}\text { Pedalidade/ } \\
\text { Agregação }\end{array}$ & Poro & Feição pedológica ${ }^{(2)}$ \\
\hline Ap & Uma & $\begin{array}{c}\text { Porfírica } \\
\text { aberta }\end{array}$ & $\begin{array}{l}\text { Mosaico e salpicada, } \\
\text { poroestriada, } \\
\text { granoestriada } \\
\text { e estriada; muita }\end{array}$ & $\begin{array}{l}\quad \text { Sopé (P1) } \\
\text { Granular e em } \\
\text { blocos subangulares } \\
\text { moderadamente } \\
\text { desenvolvidos }\end{array}$ & $\begin{array}{l}\text { Interagregados: } \\
\text { canais, câmaras } \\
\text { e fissuras. } \\
\text { Intragregados: } \\
\text { fissuras }\end{array}$ & $\begin{array}{l}\text { Nódulos ferruginosos } \\
\text { (raros) e ferriargilosos } \\
\text { (muitos). } \\
\text { Preenchimentos } \\
\text { de calcita acicular } \\
\text { e nodular (ocasionais). } \\
\text { Feições de } \\
\text { excremento (muitas) }\end{array}$ \\
\hline Bt2 & Uma & $\begin{array}{c}\text { Porfírica } \\
\text { aberta }\end{array}$ & $\begin{array}{l}\text { Salpicada, } \\
\text { granoestriada, } \\
\text { poroestriada, } \\
\text { crescente, paralelo } \\
\text { estriada e estriada } \\
\text { cruzada; abundante }\end{array}$ & $\begin{array}{l}\text { Blocos subangulares } \\
\text { moderados a } \\
\text { fortemente } \\
\text { desenvolvidos }\end{array}$ & $\begin{array}{l}\text { Inter e } \\
\text { intragregados: } \\
\text { fissuras, canais } \\
\text { e cavidades }\end{array}$ & $\begin{array}{l}\text { Nódulos ferruginosos } \\
\text { (ocasionais), } \\
\text { ferromanganosos } \\
\text { ocasionais) e } \\
\text { (ferriargilosos (muitos). } \\
\text { Preenchimentos, } \\
\text { revestimentos, quase } \\
\text { revestimentos, } \\
\text { hiporrevestimentos por } \\
\text { argilas e óxidos de ferro } \\
\text { (muito abundantes). } \\
\text { Preenchimentos de } \\
\text { calcita acicular (muitos) }\end{array}$ \\
\hline Ap & Uma & $\begin{array}{l}\text { Porfírica } \\
\text { fechada }\end{array}$ & $\begin{array}{l}\text { Salpicada grânida } \\
\text { comum, poroestriada } \\
\text { e granoestriada; } \\
\text { ocasional }\end{array}$ & $\begin{array}{l}\quad \text { Terço médio (P2) } \\
\text { Granular e em blocos } \\
\text { subangulares } \\
\text { moderadamente } \\
\text { desenvolvidos }\end{array}$ & $\begin{array}{l}\text { Interagregados: } \\
\text { canais, câmaras } \\
\text { e fissuras. } \\
\text { Intragregados: fissuras }\end{array}$ & $\begin{array}{l}\text { Nódulos ferruginosos (raros) } \\
\text { e ferriargilosos (muitos). } \\
\text { Preenchimentos densos } \\
\text { completos de material fino } \\
\text { resultante de atividade } \\
\text { biológica (muitos). Feições } \\
\text { de excremento (muitas). } \\
\text { Preenchimentos de calcita } \\
\text { acicular e nodular } \\
\text { (ocasionais a raros). } \\
\text { Preenchimentos densos } \\
\text { completos e incompletos } \\
\text { com argila } \\
\text { microlaminar (raros) }\end{array}$ \\
\hline Bt2 & Uma & $\begin{array}{c}\text { Porfírica } \\
\text { duplo espaçada }\end{array}$ & $\begin{array}{l}\text { Poroestriada, } \\
\text { granoestriada, } \\
\text { reticular estriada } \\
\text { e salpicada grânida; } \\
\text { abundante }\end{array}$ & $\begin{array}{l}\text { Blocos subangulares } \\
\text { moderados a } \\
\text { fortemente } \\
\text { desenvolvidos }\end{array}$ & $\begin{array}{l}\text { Interagregados: } \\
\text { canais, câmaras } \\
\text { e fissuras. } \\
\text { Intragregados: } \\
\text { cavidades e fissuras }\end{array}$ & $\begin{array}{l}\text { Nódulos ferruginosos } \\
\text { (ocasionais), } \\
\text { ferromanganosos } \\
\text { (ocasionais) e } \\
\text { ferriargilosos (muitos). } \\
\text { Revestimentos, } \\
\text { hiporrevestimentos e } \\
\text { preenchimentos densos } \\
\text { de argila (muitos). } \\
\text { Preenchimentos de } \\
\text { calcita acicular e } \\
\text { nodular (raros) }\end{array}$ \\
\hline $\mathrm{A} 1+\mathrm{A} 2$ & $2 \mathrm{Uma}$ & $\begin{array}{l}\text { Pórfiro- } \\
\text { enáulica }\end{array}$ & $\begin{array}{l}\text { Poroestriada, } \\
\text { granoestriada, } \\
\text { comum e salpicada } \\
\text { grânida; abundante }\end{array}$ & \begin{tabular}{l}
\multicolumn{1}{c}{ Topo (P3) } \\
Granular e em \\
blocos subangulares \\
moderadamente \\
desenvolvidos
\end{tabular} & $\begin{array}{l}\text { Interagregados: } \\
\text { empacotamento, } \\
\text { fissuras, canais e } \\
\text { câmaras. Intragregados: } \\
\text { cavidades e } \\
\text { microfissuras }\end{array}$ & $\begin{array}{l}\text { Nódulos ferruginosos (raros) } \\
\text { e ferriargilosos (muitos). } \\
\text { Preenchimentos e } \\
\text { revestimentos de poros } \\
\text { com argila iluvial (raros). } \\
\text { Preenchimentos soltos } \\
\text { descontínuos de canais } \\
\text { com agregados. Feições } \\
\text { de excremento (ocasionais) }\end{array}$ \\
\hline
\end{tabular}


Quadro 7. Cont.

\begin{tabular}{|c|c|c|c|c|c|c|}
\hline Hor. & Zona & $\begin{array}{l}\text { Distribuição } \\
\text { relativa }\end{array}$ & $\mathbf{F B}^{(1)}$ & $\begin{array}{l}\text { Pedalidade/ } \\
\text { Agregação }\end{array}$ & Poro & Feição pedológica ${ }^{(2)}$ \\
\hline \multirow[t]{2}{*}{ Bi1 } & \multirow[t]{2}{*}{ Duas } & $\begin{array}{l}\text { Zona (A): } \\
\text { porfírica duplo } \\
\text { espaçada }\end{array}$ & $\begin{array}{l}\text { Zona (A): poroestriada, } \\
\text { granoestriada, } \\
\text { salpicada grânida, } \\
\text { paralelo estriada, } \\
\text { reticulada cruzada; } \\
\text { muito abundante }\end{array}$ & $\begin{array}{l}\text { Zona (A): blocos } \\
\text { subangulares, } \\
\text { fortemente } \\
\text { desenvolvidos }\end{array}$ & $\begin{array}{l}\text { Zona (A): interagregados: } \\
\text { planares, canais e } \\
\text { câmaras. Intragregados: } \\
\text { cavidades e fissuras }\end{array}$ & $\begin{array}{l}\text { Zona (A): revestimentos, } \\
\text { hiporrevestimentos e quase } \\
\text { revestimentos de poros } \\
\text { e de grãos com argilas e } \\
\text { e óxidos de ferro (ocasionais). } \\
\text { Preenchimentos densos de } \\
\text { argila (ocasionais). } \\
\text { Nódulos ferruginosos e } \\
\text { ferromanganosos (muitos) e } \\
\text { ferriargilosos (abundantes) }\end{array}$ \\
\hline & & $\begin{array}{c}\text { Zona (B): } \\
\text { Pórfiro-enáulica }\end{array}$ & $\begin{array}{l}\text { Zona (B): Poroestriada, } \\
\text { granoestriada, } \\
\text { salpicada grânida, } \\
\text { paralelo estriada e } \\
\text { estriada cruzada; } \\
\text { abundante }\end{array}$ & $\begin{array}{l}\text { Zona (B): granular, } \\
\text { e blocos subangulares, } \\
\text { moderadamente } \\
\text { desenvolvidos. }\end{array}$ & $\begin{array}{l}\text { Zona (B): interagregados: } \\
\text { empacotamento, canais } \\
\text { e câmaras. Intragregados: } \\
\text { cavidades }\end{array}$ & $\begin{array}{l}\text { Zona (B): revestimentos, } \\
\text { hiporrevestimentos e } \\
\text { quase revestimentos de } \\
\text { argilas e óxidos de ferro } \\
\text { (ocasionais). Preenchimentos } \\
\text { densos completos de argila } \\
\text { (ocasionais). Nódulos } \\
\text { ferruginosos eferromanganosos } \\
\text { (muitos) e ferriargilosos } \\
\text { (abundantes) }\end{array}$ \\
\hline
\end{tabular}

Hor: horizonte; ${ }^{(1)} \mathrm{FBI}$ : fábrica birrefringente; ${ }^{(3)}$ rara (<2\%); ocasional (2 a $\left.5 \%\right)$; muita (5 a $\left.10 \%\right)$; abundante (10 a $\left.20 \%\right)$; muito abundante (> $20 \%)$.

$30 \%$ do volume. Os poros são principalmente do tipo canais, formados pela atividade biológica, além de câmaras e algumas fissuras, essas últimas predominantes dentro dos agregados compostos de matéria orgânica, argilominerais e óxidos de Fe. Entre as feições pedológicas ocorrem preenchimentos soltos contínuos e descontínuos de excrementos (Figura 2a), além de preenchimentos ocasionais de poros com calcita acicular e nodular.

No horizonte Bt2 do P1, apresentam-se porosidades fissurais inter e intragregados, com distribuição relativa porfírica aberta, pedalidade moderada a forte e microestrutura em blocos subangulares. O material fino, constituído por argilominerais e óxidos de Fe, representa cerca de $70 \%$, enquanto o material grosso, onde predominam grãos de quartzo, é de cerca de $20 \%$ da lâmina (relação g/f com limite de $2 \mu \mathrm{m}$ de 2/7). Abundantes revestimentos e preenchimentos microlaminares de argila com orientação forte e contínua, resultantes do processo de iluviação (Figura 2b), identificados no campo como cerosidade (Embrapa, 2013), associados a preenchimentos contínuos e descontínuos de poros por calcita acicular e nodular, constituem a característica mais marcante desse horizonte e é considerada por Chadwick et al. (1995) como indicativa de solos poligenéticos.

Segundo Reheis (1987), a existência de feições de iluviação de argila juntamente com acúmulos de $\mathrm{CaCO}_{3}$ secundário em um mesmo solo indica importantes mudanças climáticas. Enquanto recobrimentos de revestimentos de argila por carbonatos de cálcio sugerem mudanças de um período de úmido para um período seco (Gile et al., 1966), situações onde feições de iluviação de argila se justapõem a acumulações de $\mathrm{CaCO}_{3}$ indicam que após um longo período seco, durante o qual o $\mathrm{CaCO}_{3}$ acumulou, sobreveio um clima mais úmido que favoreceu a argiluviação (Khormali et al., 2003).

No P2, o horizonte Ap apresenta relação g/f (com limite de $2 \mu \mathrm{m}$ ) de $2 / 3$, possuindo distribuição relativa porfírica fechada com material fino constituído por matéria orgânica, argilominerais e óxidos de Fe. Com pedalidade moderadamente desenvolvida, apresenta microestrutura composta constituída pelo tipo granular e em blocos subangulares, parcialmente acomodados. Dentre as feições pedológicas, destacamse os agregados formados pela atividade biológica, além de revestimentos e preenchimentos com argila microlaminar, além de preenchimentos ocasionais de calcita acicular (Figura 3a) associados a nódulos carbonáticos.

No horizonte Bt2 do P2, apresenta-se evidente expressão das feições de iluviação de argila, com preenchimentos densos incompletos e completos de argila (Figura 3b), com orientação moderada a forte, alguns dos quais em forma de crescente, além de revestimentos e hiporrevestimentos de grãos e poros (comuns). A distribuição relativa é porfírica duplo espaçada, com pouco material grosso dominado por grãos de quartzo pobremente selecionados (relação g/f com limite de $2 \mu \mathrm{m}$ de 5/9). A microestrutura é formada por agregados em blocos 
(a)

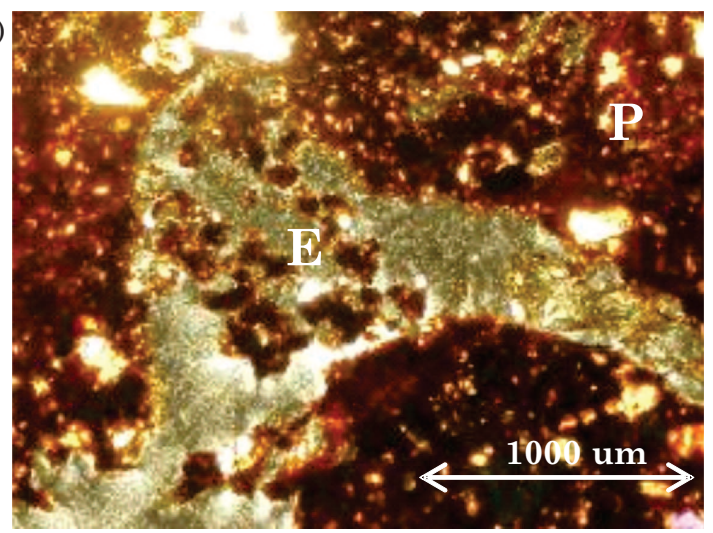

(b)

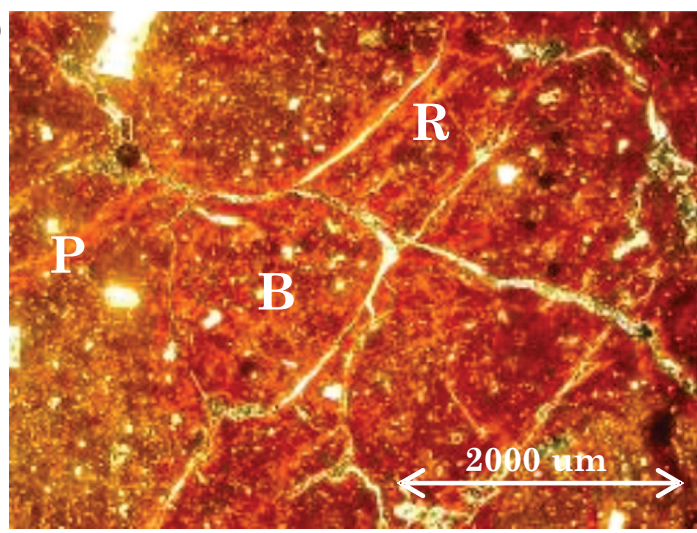

Figura 2. Fotomicrografias em luz polarizada cruzada (XPL) do P1. a) Feições de excremento em canal (E) e distribuição relativa porfírica aberta (P), no horizonte Ap. b) Microestrutura em blocos subangulares (B) com revestimentos $(R)$ e preenchimentos de argila e óxidos de ferro $(P)$, no horizonte Bt2.

(a)

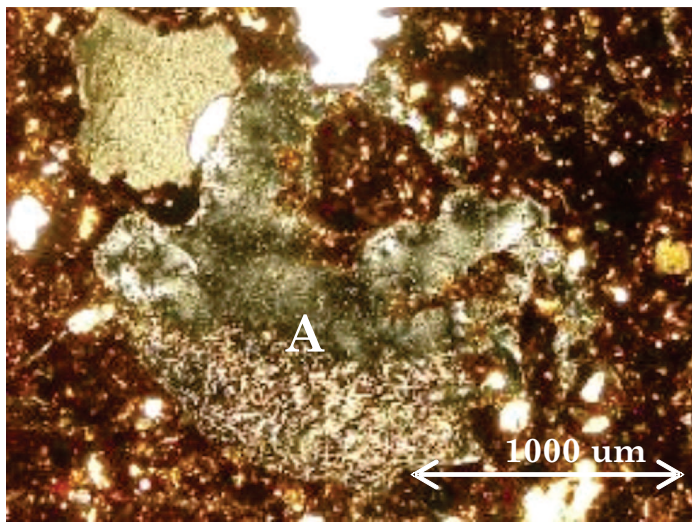

(b)

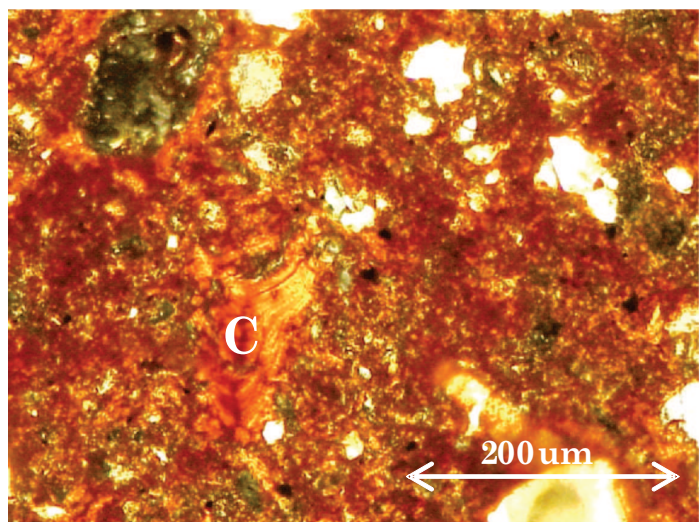

Figura 3. Fotomicrografias em luz polarizada cruzada (XPL) do P2. a) Preenchimento solto descontínuo de poro por calcita acicular (A), no horizonte Ap. b) Revestimento crescente de argila iluvial (C), no horizonte Bt2.

subangulares moderadamente a fortemente desenvolvidos separados por canais, fissuras e câmaras. Compostos essencialmente por argilominerais e óxidos de $\mathrm{Fe}$, apresentam fábricas birrefringentes dos tipos salpicada grânida, poroestriada, granoestriada e reticular estriada, todas abundantes. As feições cristalinas, com preenchimentos soltos contínuos e descontínuos de calcita acicular nos canais, ocorrem em pequena quantidade.

No P3, evidencia-se horizonte A (A1 + A2) com distribuição pórfiro-enáulica composta por agregados granulares e blocos subangulares com pedalidade moderada, separados por canais, câmaras e fissuras, que representam cerca de $30 \%$ da lâmina. O material fino, formado por matéria orgânica, argilominerais e óxidos de Fe, é dominante (60 \%). No horizonte Bi1 do P3, duas zonas são identificadas: uma com distribuição relativa porfírica (aproximadamente $75 \%$ da lâmina) e outra com distribuição relativa pórfiro-enáulica (Figura 4a), ambas com predomínio de quartzo como material grosso, e material fino constituído essencialmente por argilominerais e óxidos de Fe. Preenchimentos, revestimentos, hiporrevestimentos e quase revestimentos de poros e de grãos com argilominerais são observados apenas ocasionalmente nessa zona. Os preenchimentos por calcita acicular no P3 são raros, ao contrário do verificado nos demais perfis, indicando menor evolução pedogenética desse perfil, haja vista a formação das precipitações carbonáticas ocorrer em escala de tempo relativamente curta (Courty \& Fédoroff, 1985). Nódulos de Fe de 1,0 a 0,1 mm de diâmetro são comumente observados (Figura 4b), diferindo do P1 e P2, onde a ocorrência era ocasional. Segundo Oliveira et al. (2001), a observação de nódulos concêntricos com evidentes sinais de recapeamento por novos aportes de Fe indica que o processo de formação dos nódulos ainda está ativo. Representando pequena parcela da lâmina (25\%), a zona pórfiro-enáulica distingue-se da anterior, sobretudo, pela presença de microagregados granulares associados aos blocos subangulares. 
(a)

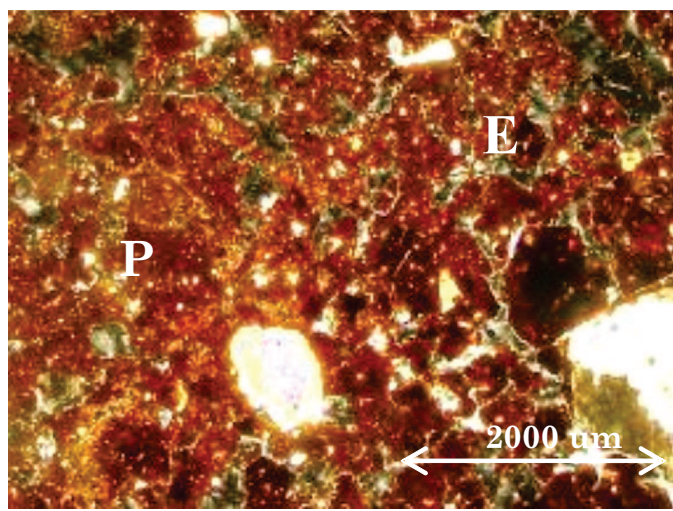

(b)

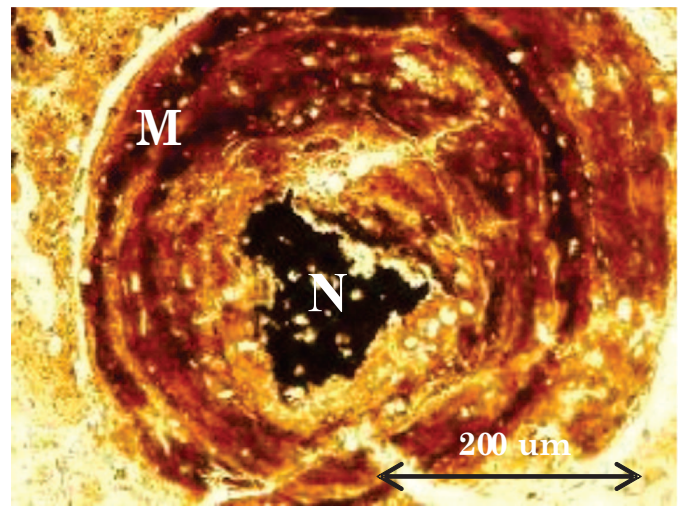

Figura 4. Fotomicrografias do horizonte Bi1 do P3. a) Distribuições relativas porfírica (P) e pórfiro-enáulica (E), vistas sob luz polarizada cruzada (XPL). b) Detalhe de nódulo de ferro concêntrico (N) separado da matriz por microfissura (M), observado sob luz polarizada plana (PPL).

\section{Classificação dos solos e pedogênese}

O perfil longitudinal plano-convexo-plano (P1-P2P3), a elevação, a drenagem, a topografia suave ondulada e a estabilidade da área conduzem a uma evolução diferenciada dos solos, a partir do intemperismo das rochas calcárias. A identificação dos horizontes diagnósticos B textural em P1 e P2, e B incipiente em P3; a maior profundidade do solum no $\mathrm{P} 1$; os menores valores estimados da atividade de argila nos horizontes $\mathrm{Bt} 1$ e Bt2, em P1; o menor valor de ki no horizonte no Bt1 do $\mathrm{P} 1$; e a micromorfologia dos horizontes Bt2 dos perfis $\mathrm{P} 1 \mathrm{e}$ P2 com feições de iluviação de argila abundantes, indicam a seguinte ordem de evolução pedogenética dos perfis: $\mathrm{P} 1>\mathrm{P} 2>\mathrm{P} 3$.

Situado em posição de sopé e superfície plana e mais baixa em relação aos demais, favorável à infiltração de água no perfil e à adição de bases e matéria orgânica provenientes das partes mais altas, o P1 apresenta gradiente textural de 1,6 e cerosidade moderada a forte, caracterizando a argiluviação como o processo pedogenético predominante. Com sequência de horizontes A-Bt, com horizonte A chernozêmico sobrejacente a um horizonte B com predomínio de cores no matiz 2,5 YR e incremento de argila que atende às exigências para a identificação de horizonte B textural, o P1 é classificado como Argissolo Vermelho. Em nível de grande grupo, o perfil é enquadrado como eutrófico, em razão do $\mathrm{V} \geq$ $50 \%$, e como nitossólico, em nível de subgrupo, por atender os requisitos de espessura, estrutura e cerosidade, para o reconhecimento de um horizonte $\mathrm{B}$ nítico, diferindo desse, entretanto, por apresentar relação textural maior que 1,5 e pela presença de policromia.

$\mathrm{Na}$ meia encosta da mesma vertente, o P2 apresenta sequência de horizontes A-E-Bt, com horizonte diagnóstico superficial A parcialmente decapitado pela erosão, favorecida pela declividade e convexidade da superfície. Também neste perfil, verifica-se a ocorrência de argiluviação como processo pedogenético dominante, caracterizado pela presença de um horizonte de eluviação sobrejacente a um horizonte B com cerosidade comum e expressivo incremento de argila, sequência incomum em solos derivados de calcário. Com A moderado e horizonte B textural com cores vermelhas nos matizes 5YR e 2,5YR, o P2 é classificado como Argissolo Vermelho distrófico típico por causa do $\mathrm{V}<50 \%$ e da falta de características intermediárias para outras classes de solos.

Em superfície plana no topo da encosta, o P3 é considerado o de menor grau de evolução entre os perfis da topossequência, o que se verifica em escala macromorfológica pela agregação em blocos subangulares fracamente desenvolvida no horizonte $\mathrm{B}$, ocorrência de pontuações de carbonatos no perfil e na presença de calhaus e matacões de natureza calcária, tanto em superfície como em subsuperfície. Também em escala micromorfológica, a menor expressividade das feições de iluviação de argila e de precipitações carbonáticas em relação aos demais perfis, pressupõe o menor grau de evolução pedogenética do P2. Ao contrário dos perfis $\mathrm{P} 1$ e P2, onde o gradiente textural deve-se, sobretudo, ao processo de argiluviação, no P3 o incremento de argila em profundidade deve ser resultante de variação de constituição do material de origem.

Com A proeminente e sequência de horizontes ABi, o P3 é classificado como Cambissolo no nível categórico de ordem e Háplico, no nível de subordem. Já no nível de grande grupo, o P3 é identificado como Tb eutrófico por apresentar argila de atividade baixa e saturação por bases alta $(\mathrm{V} \geq 50 \%)$, na maior parte dos primeiros $100 \mathrm{~cm}$ do horizonte B (inclusive BA) e no subgrupo, como típico.

Para todos os perfis, em razão dos valores de atividade da argila nos horizontes Bt1 (P1 e P2) e Bi (P3), próximos ao limite para atividade alta, aplicase a classe de atividade média $(\mathrm{Tm})$ para valores entre 17 e $27 \mathrm{cmol}_{\mathrm{c}} \mathrm{kg}^{-1}$ de argila, no quinto nível taxonômico do SiBCS, para diferenciá-los de outros 
Argissolos Vermelhos e Cambissolos Háplicos, validando proposta recente do SiBCS (Embrapa, 2013).

\section{CONCLUSÕES}

1. A evolução dos solos sob as condições climáticas da Serra da Bodoquena não favorece a acumulação de $\mathrm{CaCO}_{3}$ em quantidade suficiente para reconhecimento do horizonte cálcico, petrocálcico ou de caráter carbonático e hipocarbonático nos perfis estudados, embora desenvolvidos de materiais de origem de natureza carbonática.

2. Os perfis de solos estudados são poligenéticos e apresentam diferentes graus de pedogênese, sendo o mais evoluído o P1, localizado no sopé em superfície linear; seguido do P2, em meia encosta convexa; e do P3, que está em paisagem de topo e com relevo plano, com o menor grau de pedogênese.

3. A caracterização micromorfológica é relevante para indicar a evolução de processos pedogenéticos nos perfis, com destaque para a organização estrutural, as feições de iluviação de argila e as acumulações de $\mathrm{CaCO}_{3}$ secundário.

4. Os perfis 1,2 e 3 são classificados, respectivamente, como: Argissolo Vermelho eutrófico nitossólico, Argissolo Vermelho distrófico típico e Cambissolo Háplico Tb eutrófico típico. No quinto nível, aplica-se a classe de atividade de argila média Tm para todos os perfis, validando proposta recente do SiBCS.

\section{AGRADECIMENTOS}

Ao CPGA-CS, à UFRRJ e ao CNPq, Edital MCT/ CNPq 14/2009, pelo apoio financeiro; e ao Laboratório de Micromorfologia do Solo da ESALQ, por todo o suporte técnico.

\section{LITERATURA CITADA}

ALMEIDA, F.F.M. Geologia da Serra da Bodoquena (Mato Grosso), Brasil. Bol. Divisão Geol. Mineral., DNPM, 219:196, 1965.

ANJOS, L.H.C.; FERNANDES, M.R.; PEREIRA, M.G. \& FRANZMEIER, D.P. Landscape and pedogenesis of an Oxisol-Inceptisol-Ultisol sequence in Southeastern Brazil. Soil Sci. Soc. Am. J., 62:1651-1658, 1998.

BENITES, V.M.; MADARI, B. \& MACHADO, P.L.O.A. Extração e fracionamento quantitativo de substâncias húmicas do solo: um procedimento simplificado de baixo custo. Rio de Janeiro, Embrapa Solos, 2003. 7p. (Comunicado Técnico, 16)
BOERO, V.; PREMOLI, A.; MELIS, P.; BARBERIS, E. \& ARDUINO, E. Influence of climate on the iron oxide mineralogy of Terra Rossa. Clays Clay Miner., 40:8-13, 1992.

BOGGIANI, P.C.; COIMBRA, A.M. \& HACHIRO, J. Evolução paleogeográfica do Grupo Corumbá (Neoproterozoico). In: CONGRESSO BRASILEIRO DE GEOLOGIA, 39., Salvador, 1996. Anais ...Salvador, SBG, 1996. v.6, p.132134.

BOSÁK, P. Karst processes from the beginning to the end: How can they be dated? Speleogenesis Evol. Karst Aquifers, 1:1-24, 2003.

BRAIDA, J.A.; CAMARGO, F.A.O.; ROSSO, I.J.; GIANELLO, C. \& MEURER, E.J. Comparação de métodos de determinação da disponibilidade de fósforo do solo para as plantas. R. Bras. Ci. Solo, 20:345-347, 1996.

BRASIL. Ministério das Minas e Energia. Departamento Nacional de Produção Mineral. Projeto RADAMBRASIL: Folha SF.21 - Campo Grande; geologia, geomorfologia, pedologia, vegetação e uso potencial da terra. Rio de Janeiro, 1982. 416p. (Levantamento de Recursos Minerais, 28)

BULLOCK, P.; FEDOROFF, N.; JONGERIUS, A.; STOOPS, G. \& TURSINA, T. Handbook for soil thin section description. Wolverhampton, Waine Research Publications, 1985. 152p.

CAMPOS, M.C.C.; RIBEIRO, M.R.; SOUZA JÚNIOR, V.S.; RIBEIRO FILHO, M.R. \& COSTA, E.U.C. Segmentos de vertente e atributos do solo de uma topossequência na região de Manicoré, AM. R. Ci. Agron., 41:501-510, 2010.

CAMPOS, M.C.C.; RIBEIRO, M.R.; SOUZA JUNIOR, V.S.; RIBEIRO FILHO, M.R. \& ALMEIDA, M.C. Relações solosuperfície geomórfica em uma topossequência várzeaterra firme na região de Humaitá (AM). R. Bras. Ci. Solo, 36:325-336, 2012 .

CASTRO, S.S.; COOPER, M.; SANTOS, M.C. \& VIDALTORRADO, P. Micromorfologia do solo: Bases e aplicações. In: CURI, N.; MARQUES, J.J.; GUILHERME, L.R.G.; LIMA, J.M.; LOPES, A.S. \& ALVAREZ V., V.H., eds. Tópicos em ciência do solo. Viçosa, MG, Sociedade Brasileira de Ciência do Solo, 2003. v.3. p.107-164.

CHADWICK, O.A.; NETTLETON, W.D. \& STAIDL, G.J. Soil polygenesis as a function of quaternary climate change, Northern Great Basin, U.S.A. Geoderma, 68:1-26, 1995.

CORRÊA, M.M.; KER, J.C.; MENDONÇA, E.S.; RUIZ, H.A. \& BASTOS, R.S. Atributos físicos, químicos e mineralógicos de solos da região das várzeas de Sousa (PB). R. Bras. Ci. Solo, 27:311-324, 2003.

COURTY, M.A. \& FÉDOROFF, N. Micromorphology of recent and buried soils in a semiarid region of northwestern Índia. Geoderma, 35:287-332, 1985.

CUNHA, T.J.F.; MANZATTO, C.V.; RIBEIRO, L.P.; PALMIERI, F. \& CALDERANO FILHO, B. Diferenciação pedológica e alteração de rochas calcárias na região de Irecê (BA). Pesq. Andamento, 6:1-6, 1999. 
DAL' BÓ, P.F.F. \& BASILICI, G. Estimativas de paleoprecipitação e gênese de feições cálcicas e argílicas em paleossolos da Formação Marília (Neocretáceo da Bacia Bauru). Geociências, 29:33-47, 2010.

EBELling, A.G.; ANJOS, L.H.C.; PEREIRA, M.G.; PINHEIRO, E.F.M. \& VALLADARES, G.S. Substâncias húmicas e relação com atributos edáficos. Bragantia, 70:157-165, 2011.

EMPRESA BRASILEIRA DE PESQUISA AGROPECUÁRIA EMBRAPA. Levantamento exploratório-reconhecimento de solos do Estado do Ceará. Fortaleza, 1973. v.2.

EMPRESA BRASILEIRA DE PESQUISA AGROPECUÁRIA . EMBRAPA. Manual de métodos de análise de solo. Rio de Janeiro, Centro Nacional de Pesquisa de Solos, 1997. $212 \mathrm{p}$.

EMPRESA BRASILEIRA DE PESQUISA AGROPECUÁRIA EMBRAPA. Centro Nacional de Pesquisa do Solo. Sistema brasileiro de classificação de solos. 2.ed. Rio de Janeiro, Embrapa Solos, 2006. 306p.

EMPRESA BRASILEIRA DE PESQUISA AGROPECUÁRIA EMBRAPA. Centro Nacional de Pesquisa do Solo. Levantamento de reconhecimento de baixa intensidade dos solos do Município de Bonito, Estado do Mato Grosso do Sul. Rio de Janeiro, Embrapa Solos, 2007. 183p. (Boletim de Pesquisa e Desenvolvimento/Embrapa Solos)

EMPRESA BRASILEIRA DE PESQUISA AGROPECUÁRIA EMBRAPA. Sistema brasileiro de classificação de solos. 3.ed. Brasília, 2013. 353p.

FONTANA, A.; PEREIRA, M.G.; NASCIMENTO, G.B.N.; ANJOS, L.H.C. \& EBELING, A.G. Matéria orgânica em solos e tabuleiros na Região Norte Fluminense - RJ. Flor. Amb., 8:114-119, 2001.

FONTANA, A.; PEREIRA, M.G.; ANJOS, L.H.C. \& BENITES, V.M. Quantificação e utilização das frações húmicas como característica diferencial em horizontes diagnósticos de solos brasileiros. R. Bras. Ci. Solo, 34:1241-1257, 2010.

GILE, L.H.; PETERSON, F.F. \& GROSSMAN, R.B. Morphological and genetic sequences of carbonate accumulation in desert soils. Soil Sci., 101:347-354, 1966.

KOHLER, H.C. Geomorfologia cárstica. In: GUERRA, J.T. \& CUNHA, S.B., orgs. Geomorfologia: Uma atualização de bases e conceitos. Rio de Janeiro, Bertrand Brasil, 1994. p.309-334.

KHORMALI, F.; ABTAHI, A.; MAHMOODI, S. \& STOOPS, G. Argillic horizon development in calcareous soils of arid and semiarid regions of southern Iran. Catena, 53:273301, 2003.

LYNCH, L.S. Gênese e geoquímica de solos em ambiente cárstico no cerrado da região de Planaltina de Goiás. Viçosa, MG, Universidade Federal de Viçosa, 2009. 167p. (Tese de Doutorado)

MACK, G.H.; COLE, D.R.; CALVIN JAMES, W.; GIORDANO, T.H. \& SALYARDS, S.L. Stable oxygen and carbon isotopes of pedogenic carbonate as indicators of PlioPleistocene paleoclimate in the Southern Rio Grande rift, South-Central New Mexico. Am. J. Sci., 294:621-640, 1994.
MANZATTO, H.R.H. Dinâmica da matéria orgânica em solo Glei Pouco Húmico cultivado com arroz inundado no Vale do São João. Itaguaí, Universidade Federal Rural do Rio de Janeiro, 1990. 143p. (Dissertação de Mestrado)

MEHRA, O.P. \& JACKSON, M.L. Iron oxide removal from soil and clays by dithionite - citrate system buffered with sodium bicarbonate. Clays Clay Miner., 5:317-327, 1960.

MTAMBANENGWE, F.; MAPFUMO, P. \& KIRCHMAN, H. Decomposition of organic matter in soil as inûuenced by texture and pore size distribution. In: BATIONO, A., ed. Managing nutrient cycles to sustain soil fertility in SubSaharan Africa. Nairobi, Academy Science Publishers and TSBF CIAT, 2004. p.261-275.

NIZEYIMANA, E. \& BICKI, T.J. Soil and landscape relationships in the North Central region of Rwanda, East-Central Africa. Soil Sci., 153:225-236, 1992.

OLIVEIRA, C.V.; KER, J.C.; CURI, N.; DUARTE, M.N. \& FONTES, L.E.F. Caracterização de concreções ferromanganosas de solos de calcário no norte do Estado de Minas Gerais. R. Bras. Ci. Solo, 25:565-574, 2001.

PEREIRA, M.G.; SCHIAVO, J.A.; FONTANA, A.; DIAS NETO, A.H.; \& MIRANDA, L.P.M. Caracterização e classificação de solos em uma topossequência sobre calcário na Serra da Bodoquena, MS. R. Bras. Ci. Solo, 37:25-36, 2013.

REHEIS, M.C. Climatic implications of alternating clay and carbonate formation in semiarid soils of south-central Montana. Quartern. Res., 27:270-282, 1987.

RUELLAN, A. Petrocalcic horizons: Soil with. In: LAL, R., ed. Encyclopedia of Soil Science. Boca Raton, Fl, USA, CRC Press, 2006. 2.ed. p.1266-1269.

SANCHEZ, R.B.; MARQUES JÚNIOR, J.; SOUZA, Z.M.; PEREIRA, G.T. \& MARTINS FILHO, M.V. Variabilidade espacial de atributos do solo e de fatores de erosão em diferentes pedoformas. Bragantia, 68:1095-1103, 2009.

SANTOS, R.D.; LEMOS, R.C.; SANTOS, H.G.; KER, J.C. \& ANJOS, L.H.C. Manual de descrição e coleta de solo no campo. 5.ed. Viçosa, MG, Sociedade Brasileira de Ciência do Solo/Embrapa Solos, 2005. 100p.

SCHULZE, D.G. The influence of aluminum on iron oxides: VII. Unit-cell dimensions of Al-substituted goethites and estimation of $\mathrm{Al}$ from them. Clays Clay Miner., 32:36-44, 1984.

SCHWERTMANN, U. \& TAYLOR, R.M. Iron oxides. In: DIXON, J.B. \& WEED, S.B., eds. Minerals in soil environments. Madison, Soil Science Society of America, 1989. p.379-438.

SCHWERTMANN, U. Differenzierung der Eisenoxide des Bodens durch Extraktion mit Ammoniumoxalatlösung. Zeitschrift fuer Pflanzenernaehrung-Düngund Bodenkunde, Weinheim, 105:94-202, 1964.

SEDOV, S.; SOLLERO-REBOLLEDO, E.; FEDICK, S.L.; PIPUIG, T.; VALLEJO GÓMEZ, E. \& FLORESDELGADILHO, M.L. Micromorphology of a soil catena in Yucatán: Pedogenesis and geomorphological processes in a tropical karts landscape. In: KAPUR, S.; MERMUT, A. \& STOOPS, G., eds. New trends in soil micromorphology. London, Springer, 2008. p.19-38. 
SHINZATO, E. O carste da área de proteção ambiental de Lagoa Santa (MG) e sua influência na formação de solos. Campos dos Goytacazes, Universidade Estadual do Norte Fluminense, 1998. 99p. (Dissertação de Mestrado)

SILVA, F.J. Classificação de alguns solos identificados na Chapada do Apodi. Seropédica, Universidade Federal Rural do Rio de Janeiro, 1973. 106p. (Dissertação de Mestrado)

STEVENSON, F.J. Humus chemistry: Genesis, composition, reactions. 2.ed. New York, John Wiley \& Sons, 1994. 496p.
STOOPS, G. Guidelines for analysis and description of soil and regolith thin sections. Madison, Soil Science Society of America, 2003. 180p.

TROEH, F.R. Landform equations fitted to contour maps. Soil Sci. Soc. Am. J., 263:616-27, 1965.

ZASLAVSKY, D. \& ROGOWSKI, A.S. Hydraulic and morphological implications of anisotropy and infiltration in soil profile development. Soil Sci. Soc. Am. Proc., 33:594599, 1969. 